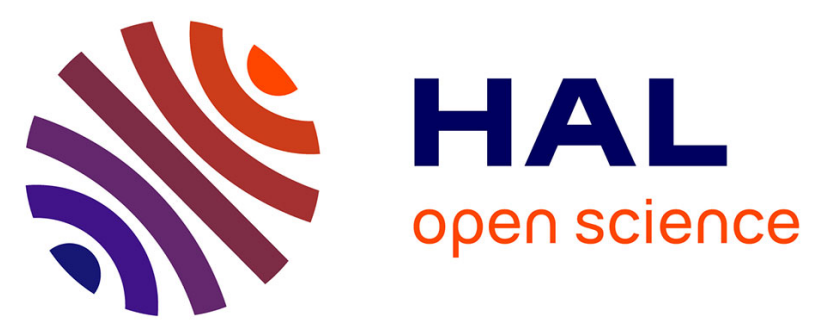

\title{
Physicochemical, setting, rheological, and mechanical properties of a novel bio-composite based on apatite cement, bioactive glass, and alginate hydrogel
}

\author{
H. Mabroum, H. Noukrati, H. Ben Youcef, B. Lefeuvre, H. Oudadesse, A.
} Barroug

\section{To cite this version:}

H. Mabroum, H. Noukrati, H. Ben Youcef, B. Lefeuvre, H. Oudadesse, et al.. Physicochemical, setting, rheological, and mechanical properties of a novel bio-composite based on apatite cement, bioactive glass, and alginate hydrogel. Ceramics International, 2021, 47 (17), pp.23973-23983. 10.1016/j.ceramint.2021.05.106 . hal-03367782

\section{HAL Id: hal-03367782 \\ https://hal.science/hal-03367782}

Submitted on 15 Oct 2021

HAL is a multi-disciplinary open access archive for the deposit and dissemination of scientific research documents, whether they are published or not. The documents may come from teaching and research institutions in France or abroad, or from public or private research centers.
L'archive ouverte pluridisciplinaire HAL, est destinée au dépôt et à la diffusion de documents scientifiques de niveau recherche, publiés ou non, émanant des établissements d'enseignement et de recherche français ou étrangers, des laboratoires publics ou privés. 
Physicochemical, Setting, Rheological, and Mechanical Properties of a Novel BioComposite Based on Apatite Cement, Bioactive Glass, and Alginate Hydrogel

H. Mabroum ${ }^{\text {a }}$, H. Noukrati ${ }^{\text {b }}$, H. Ben youcef ${ }^{c}$, B. Lefeuvre ${ }^{\text {d }}$, H. Oudadesse ${ }^{\text {d }}$, A. Barroug ${ }^{a, b, *}$

${ }^{a}$ Cadi Ayyad University, Faculty of Sciences Semlalia, Marrakech, Morocco

${ }^{b}$ Centre of Biological and Medical Sciences, ISMB, Mohammed VI Polytechnic University (UM6P), Morocco,

${ }^{c}$ Mohammed VI Polytechnic University (UM6P), HTMR, Morocco,

${ }^{d}$ University of Rennes1, ISCR-UMR 6226, Rennes, France

\section{* Corresponding author:}

Prof. Dr. Allal BARROUG

Cadi Ayyad University, Faculty of Sciences Semlalia

BP 2390, 40000 Marrakech - Morocco

E-mail: a.barroug@uca.ma

Tel : +212662085538 


\section{Abstract}

Calcium phosphate cements (CPC) have been widely investigated as bone substitutes, owing to their attractive features in terms of physicochemical and biocompatibility properties. However, the clinical applicability of this group of biomaterials is still critically limited by its poor strength and rheological properties in terms of injectability and cohesion. The present work aims to develop novel composite cement based on calcium phosphate cement (CPC) and bioactive glass (BG), associated with sodium alginate hydrogel (Alg). The composition, microstructure, setting, rheological, and mechanical properties of this composite cement were further investigated. Evaluation of setting properties showed that BG participates crucially in the setting reaction as a calcium and phosphate provider and serves as a setting accelerator. Thus, the setting time appears lower in these cements than in the reference CPC cement: it decreases from 75 to $42 \mathrm{~min}$ as the BG content increases from 10 to $25 \mathrm{wt} \%$ and is delayed from 42 to 73 min while the Alg amount augmented from 1 to $5 \mathrm{wt} \%$. The rheological evaluation revealed that injectability was slightly improved with increasing BG content compared to the injectability of CPC, reaching a value close to $100 \%$ when combined with Alg hydrogel. The anti-washout property appeared to be weak for the CPC with or without BG, which are disintegrated in solution. The cohesiveness was significantly improved by introducing Alg hydrogel; furthermore, the addition of $5 \mathrm{wt} \%$ of alginate hydrogel induced an increase in the compressive strength about twice (7.2 MPa) higher than that of the reference CPC (4.0 MPa). According to the above findings, the addition of $\mathrm{BG}$ acts as a setting accelerator leading to a fast apatite formation, while the introduction of Alg hydrogel as a rheological promoting agent improves the injectability and cohesion. The combination of BG and Alg as additives increased the compressive strength compared to the reference cement. 
Keywords: Bioactive glass; Calcium phosphate cement; Composite; Compressive strength; Injectability; Alginate.

\section{Introduction}

Several bone diseases affect millions of people all over the world. The search for new synthetic bone grafts to treat musculoskeletal infirmities and, in particular, bone loss due to cancer, osteoporosis, or trauma, has aroused a large interest in several scientific investigations [1]. Bone autografts are regarded as the perfect standard for bone replacement due to their bone healing efficacy in terms of osteoinductive, osteoconductive, and osteogenic properties [2]. However, their use is conditioned by their limited availability and the requirement of additional surgical procedures, which increase the risk of infections and blood loss [3]. To solve these drawbacks, more research efforts have been carried to develop new bone grafts substitutes presenting improved properties to replace natural bone grafts [2]. Calcium Phosphate Cements (CPCs) are a family of bone substitutes that have proved a considerable clinical success in many dental and orthopedic applications [4]. They are used as a moldable paste to fill bone cavities, defects, or discontinuities [5]. Moreover, from the biological point of view, CPCs show excellent properties. They are biocompatible, bioresorbable, and osteoconductive [6]. However, CPCs present some limitations related to their brittleness, low injectability, and degradability [7]. Consequently, several approaches have been explored to overcome these limitations, and this was accomplished in some studies by introducing many additives such as polymers [8,9], Carbon fibers [10], Calcium sulfate [11], and Bioactive glass $[12,13]$. The incorporation of polymers in the CPC matrix has proven to be an excellent strategy for the improvement of the CPC properties such as injectability, cohesion, and mechanical strength $[14,15]$. Polymeric materials, including natural biopolymers, such as chitosan [16], gelatin [17], collagen 
[18], carboxymethyl-cellulose [19], and alginate [20], were combined with calcium phosphate cements. Synthetic polymers in specific forms, e.g. poly (lactic-co-glycolic acid) (PLGA), have been widely used to mainly improve the ductility of the brittle cement $[21,22]$. Particularly, sodium alginate has been incorporated in the cement as an additive to enhance $\mathrm{CPC}$ rheological, and mechanical properties [23, 24]. Moreover, the effect of glassy compounds as additive materials on the properties of CPCs was also investigated. Bioactive glasses constitute a group of synthetic silica-based materials, with the unique ability to directly bond to bone tissue due to the formation of a calcium phosphate layer on the glass surface $[25,26]$. The association of these materials with calcium phosphate has attracted interest due to the possibility to integrate their high bioactivity rate to the cement, thus, increasing the osteogenic potential of the material [27]. Yu et al. have reported that the incorporation of bioactive glass in the CPC matrixinduced better injectability and mechanical strength, but delayed the setting time [28]. In this light, a novel injectable apatite composite cement was developed by combining 46S6 bioactive glass (BG) and alginate hydrogel (Alg), with a reference cement CPC based on calcium carbonate (Vaterite) and calcium phosphate (Brushite). To the best of our knowledge, this work reports for the first time on the effect of the bioactive glass and sodium alginate on the CPC cement's properties, in terms of composition, microstructure, setting properties, injectability, cohesion, and compressive strength. 


\section{Materials \& Methods}

\subsection{Materials}

Calcium nitrate tetrahydrate $\left(\mathrm{Ca}\left(\mathrm{NO}_{3}\right)_{2}, 4 \mathrm{H}_{2} \mathrm{O}, \geq 99 \%\right)$, ammonium dihydrogen phosphate $\left(\mathrm{NH}_{4} \mathrm{H}_{2} \mathrm{PO}_{4}\right)$, calcium chloride dihydrate $\left(\mathrm{CaCl}_{2}, 2 \mathrm{H}_{2} \mathrm{O}, \geq 99 \%\right)$, sodium carbonate decahydrate $\left(\mathrm{Na}_{2} \mathrm{CO}_{3} \cdot 10 \mathrm{H}_{2} \mathrm{O}, \geq 99 \%\right)$, and sodium alginate $\left(\mathrm{C}_{6} \mathrm{H}_{7} \mathrm{NaO}_{6}\right.$, were purchased from Sigma-Aldrich.

Calcium metasilicate $\left(\mathrm{CaSiO}_{3}, 97 \%\right)$, trisodium tri-metaphosphate $\left(\mathrm{Na}_{3} \mathrm{P}_{3} \mathrm{O}_{9}, 95 \%\right)$, were purchased from Alfa Aesar, and sodium metasilicate pentahydrate $\left(\mathrm{Na}_{2} \mathrm{SiO}_{3}, 97 \%\right)$ from Fisher chemical.

All chemical reactants used in this study were of analytical grade and used as received.

\subsubsection{Synthesis of DCPD, $\mathrm{CaCO}_{3}$ and Bioactive Glass}

The brushite (dicalcium phosphate dihydrate - DCPD) was synthesized [29] by double decomposition from an aqueous equimolar mixture of calcium nitrate tetrahydrate $\left(\mathrm{Ca}\left(\mathrm{NO}_{3}\right)_{2}, 4 \mathrm{H}_{2} \mathrm{O}\right)$ and ammonium dihydrogen phosphate $\left(\mathrm{NH}_{4} \mathrm{H}_{2} \mathrm{PO}_{4}\right)$. Then the $\mathrm{pH}$ of the mixture was adjusted to a value of 5.5 by adding ammonia. The obtained precipitate was left to mature (5 hours), then filtered, washed with deionized water, and freezedried. The vaterite was also synthesized by double decomposition [30] from an aqueous equimolar mixture of calcium chloride dihydrate $\left(\mathrm{CaCl}_{2}, 2 \mathrm{H}_{2} \mathrm{O}\right)$ and sodium carbonate decahydrate $\left(\mathrm{Na}_{2} \mathrm{CO}_{3} \cdot 10 \mathrm{H}_{2} \mathrm{O}\right.$,). The precipitate formed was filtered, washed with deionized water, and freeze-dried.

The 46S6 bioactive glass (BG) was prepared by the melting process using calcium metasilicate $\left(\mathrm{CaSiO}_{3}\right)$, trisodium tri-metaphosphate $\left(\mathrm{Na}_{3} \mathrm{P}_{3} \mathrm{O}_{9}\right)$, and sodium metasilicate pentahydrate $\left(\mathrm{Na}_{2} \mathrm{SiO}_{3}\right)$ as inorganic precursors [31]. The reactants were mixed using a mechanical mixer for $20 \mathrm{~min}$. The homogeneous mixture was melted in a platinum $\mathrm{Pt}$ crucible and poured into a preheated die at $500{ }^{\circ} \mathrm{C}$. After cooling to room temperature, the resulting bioactive glass was ground in a mechanical agate mortar and sieved to 
obtain a particle size in the range of $100-200 \mu \mathrm{m}$. The final composition of the 46S6 bioactive glass is about $46 \mathrm{wt} \% \mathrm{SiO}_{2}, 24 \mathrm{wt} \% \mathrm{CaO}, 24 \mathrm{wt} \% \mathrm{Na}_{2} \mathrm{O}$, and $6 \mathrm{wt} \% \mathrm{P}_{2} \mathrm{O}_{5}$.

\subsubsection{Cements and composites formulation}

The composite cements investigated in this work consist of $\mathrm{DCPD}, \mathrm{CaCO}_{3}, \mathrm{BG}$ as reactive powders, and distilled water or sodium alginate hydrogel (Alg) as a liquid phase. The reference material is a mixed cement (CPC) prepared by mixing DCPD and $\mathrm{CaCO}_{3}$ in a 1:1 weight ratio with distilled water at a Liquid to Powder ratio (L/P) of 0.7 [29]. Cements combined with different amounts $(x=10,15$, and $25 \mathrm{wt} \%)$ of $\mathrm{MB}$, then named as CPC-BGx, were formulated by homogeneously mixing the reactive powders (DCPD, $\mathrm{CaCO}_{3}$, and $\mathrm{BG}$ ) with distilled water using the same $\mathrm{L} / \mathrm{P}$ ratio (Table 1 ). Additionally, CPC-BGx-Algy composites were obtained by mixing reactive powders with sodium alginate (Alg) hydrogel prepared by solubilizing Alg salts $(\mathrm{y}=1,3$, and 5 $\mathrm{wt} \%$ ) in distilled water. The samples were named CPC-BGx-Algy, where $\mathrm{x}$ and $\mathrm{y}$ are the amounts of BG and Alg respectively (Table 1).

The pastes of composite cements derived from the powders were stored immediately after preparation in a polyethylene tube at $37^{\circ} \mathrm{C}$ and $100 \%$ relative humidity and allowed to set for 48 hours. The hardened cements were dried for 5 days at $37{ }^{\circ} \mathrm{C}$ and then analyzed. Table 1 presents the different prepared composite cements.

The alginate content was only varied for the composition of CPC-BG25 as this cement showed the best characteristics in terms of chemical reaction, setting time, injectability, cohesion, and compressive strength.

Table 1. Different formulations of the composite cements and their composition.

\begin{tabular}{|c|c|c|c|c|c|}
\hline \multirow[b]{2}{*}{ Samples } & \multicolumn{3}{|c|}{ Solid-phase } & \multirow{2}{*}{$\begin{array}{l}\text { Liquid } \\
\text { phase }\end{array}$} & \multirow[b]{2}{*}{$\mathbf{L} / \mathbf{P}$} \\
\hline & $\begin{array}{l}\mathrm{CaCO}_{3} \\
(\% \mathrm{wt})\end{array}$ & $\begin{array}{l}\text { DCPD } \\
(\% \mathrm{wt})\end{array}$ & $\begin{array}{c}\text { BG } \\
(\% \mathrm{wt})\end{array}$ & & \\
\hline СРC & 50.0 & 50.0 & 0 & Distilled & 0.7 \\
\hline
\end{tabular}


water

\begin{tabular}{|c|c|c|c|c|c|}
\hline CPC-BG10 & 45.0 & 45.0 & 10 & \multirow{3}{*}{$\begin{array}{c}\text { Distilled } \\
\text { water }\end{array}$} & \multirow{3}{*}{0.7} \\
\hline CPC-BG15 & 42.5 & 42.5 & 15 & & \\
\hline CPC-BG25 & 37.5 & 37.5 & 25.0 & & \\
\hline CPC-BG25-Alg1 & 37.5 & 37.5 & 25.0 & Alg $1 \mathrm{wt} \%$ & \\
\hline CPC-BG25-Alg3 & 37.5 & 37.5 & 25.0 & Alg 3 wt $\%$ & 0.7 \\
\hline CPC-BG25-Alg5 & 37.5 & 37.5 & 25.0 & Alg 5 wt $\%$ & \\
\hline
\end{tabular}

\subsection{Methods}

\subsubsection{Physicochemical Characterization}

The chemical composition of the prepared materials was analyzed in transmission mode by Fourier transform infrared spectroscopy. The FTIR spectra were obtained at room temperature on a VORTEX spectrometer, using powdered samples embedded in $\mathrm{KBr}$ pellets. The spectral range extended from $4000 \mathrm{~cm}^{-1}$ to $400 \mathrm{~cm}^{-1}$ with a resolution of 4 $\mathrm{cm}^{-1}$.

The analyses of the crystalline phases present in the samples were performed using Xray diffraction (XRD). The diffractograms were recorded at room temperature using Rikagu D/Max-IIIB diffractometer with $\mathrm{CuK} \alpha$ source $(\lambda=1.540593 \AA$ A $)$. Data were collected between 10 and $70^{\circ}(2 \theta)$ with a step of $0.02^{\circ}$ and a scan speed of $2^{\circ} \cdot \min ^{-1}$. Scanning Electron Microscopy (SEM) (TESCAN VEGA3) coupled with an energy dispersive spectrometer (EDAX analyzer) was performed to evaluate the microstructure and elemental compositions of the formulated cements. All the specimens were coated with a thin conductive layer of carbon using a carbon coater (CRESSINGTON CARBON COATER - 108carbon/A); the morphologies were then observed. 
Porosity measurements were carried out using a mercury porosimeter (Poresizer Micromeritics Pore Sizer 9310).

\subsubsection{Setting properties}

Both setting times and setting reaction kinetics were evaluated. The initial and final setting times of the specimens were measured according to the ASTM C266-89 standard using a Gillmore testing apparatus.

To evaluate the setting reaction kinetics, the reference material (CPC) and composite cements were prepared as described above. The paste obtained by mixing the solid and liquid phases was subdivided into several samples which were then incubated in a humid environment at $37{ }^{\circ} \mathrm{C}$ for different times $(2 \mathrm{~h}, 4 \mathrm{~h}, 6 \mathrm{~h}, 24 \mathrm{~h}$, and $48 \mathrm{~h})$ and then freeze-dried to stop the setting reaction of the cement. The advancement of the setting reactions in the samples was assessed by XRD and FTIR analysis, through monitoring the evolution of reactive powders (brushite and vaterite) and the formation of apatite in the formulated materials. To compare the setting reaction of prepared cements at different incubation periods, an intensity ratio of apatite/vaterite $\left(\mathrm{I}_{\mathrm{Ap}} / \mathrm{I}_{\mathrm{Vat}}\right)$ was calculated as an indicator of apatite formation. The terms $\mathrm{I}_{\mathrm{Ap}}$ and $\mathrm{I}_{\mathrm{Vat}}$ correspond to XRD peak intensities at $26^{\circ}$ and $25.2^{\circ}$ (20 degree) of the newly formed apatite and the residual vaterite, respectively.

\subsubsection{Cohesion and Injectability testing}

To evaluate the cohesion, the cements paste, with or without polymer (CPC; CPC-BG25 and $\mathrm{CPC}-\mathrm{BG} 25-\mathrm{Alg})$, were injected immediately after preparation $(<3 \mathrm{~min})$ into a saline solution $(\mathrm{NaCl}(0.9 \mathrm{wt} \%)$. Photographs were recorded by a camera after $5 \mathrm{~min}$ and 24 hours of immersion in the solution.

The injectability of CPC, CPC-BGx, and CPC-BGx-Algy cements was evaluated by extruding a quantity of $2.0 \mathrm{~g}$ of as-prepared paste through a $5 \mathrm{~mL}$ disposable syringe, 
with an opening nozzle with a $2.0 \mathrm{~mm}$ diameter, according to the protocol described elsewhere [32,33].

The protocol consists of fitting a syringe to the programmable pumping device and insert $2.0 \mathrm{~g}$ of composite paste and then apply a constant force of $12 \mathrm{~N}$.

The injectability (I \%) is calculated according to the following Equation (1):

$$
I(\%)=\frac{m(\text { injected })}{m(\text { initial })} * 100
$$

where I, is the injectability, while m(injected), and $\mathrm{m}$ (initial) are, respectively, the weight of the paste extruded through the syringe and the paste initially contained in the syringe. All values were the average of three tests performed for each composite.

\subsubsection{Compressive strength}

The compressive strength was determined using an Instron 3369 Universal Testing Machine (crosshead speed of $1 \mathrm{~mm} \mathrm{~min}^{-1}$ ). Specimens were prepared by mixing the powders and liquid phase in a ratio $\mathrm{L} / \mathrm{P}$ of 0.7 , and the resulting pastes were placed in cylindrical silicone molds ( $8 \mathrm{~mm}$ x $16 \mathrm{~mm}$ : diameter x height). All values presented in this work are an average of three samples.

\section{Results \& Discussion}

\subsection{Physicochemical characterization of BG and prepared composite cements}

Figure1.a illustrates the FTIR spectrum of the prepared bioactive glass powder (BG) which is mainly dominated by bands attributed to the Si-O-Si bending at $525 \mathrm{~cm}^{-1}$ and bands of Si-O-Si stretching between $900-1200 \mathrm{~cm}^{-1}$ [34]. The band at $753 \mathrm{~cm}^{-1}$ is assigned to $\mathrm{P}-\mathrm{O}$ bending. The band of $\mathrm{P}-\mathrm{O}$ stretching which may appear in the range between $1000-1100 \mathrm{~cm}^{-1}$ is overlapped by the $\mathrm{Si}-\mathrm{O}-\mathrm{Si}$ stretching band [35]. The broadband observed around $3460 \mathrm{~cm}^{-1}$ is characteristic of Si-OH. The XRD diffractogram of $\mathrm{BG}$ depicted in Fig. 1.B indicates a halo between $25^{\circ}$ and $35^{\circ}(2 \theta$ degree) typical of the amorphous structure. The bioactive glass morphology examined using SEM (Fig. 1.c) consists of large particles in a block-like shape. The elemental 
composition of BG powder evaluated using EDS (Fig. 1.D) includes peaks of $\mathrm{Si}, \mathrm{Na}$, $\mathrm{Ca}$, and $\mathrm{P}$, attributed to the elements present in $\mathrm{BG}$ powder.

\section{Fig. 1}

Fig. 2 gathers for comparison the XRD patterns of the starting materials (BG, DCPD, Vaterite, and Alg), the reference cement CPC, and the composites (CPC-BG25 and CPC-BG25-Alg5).

The XRD diffractogram of DCPD shows the presence of a fine and intense peak at $12^{\circ}$ which corresponds to the diffracting planes (020), and other peaks of weaker intensity at $22^{\circ}, 24^{\circ}$, and $29^{\circ}$ attributed to $(12 \overline{1}),(040)$, and (14 $\left.\overline{1}\right)$ diffracting planes. The absence of additional peaks on the diagram attests to the purity of the synthesized DCPD (JCPDS datafile \#72-0713). The XRD pattern of the prepared vaterite shows well-defined peaks characteristic of a pure phase (JCPDS datafile \# No. 01-072-0506). The main peaks were found for $2 \theta$ values around $21^{\circ}, 24.9^{\circ}, 27^{\circ}$, and $32.8^{\circ}$ and are attributable, respectively, to the diffracting planes (004), (110), (112), and (114) of vaterite. The XRD diagram of sodium alginate (Alg) showed two weak peaks at 14.1 and $22.2^{\circ}$ revealing the presence of an amorphous structure [36].

The reference cement (CPC) X-ray diffractogram (Fig. 2) exhibits peaks that are characteristic of a poorly crystallized apatite and residual vaterite [37]. Maximum peak intensities of a poorly crystallized apatite sample were located in $2 \theta$ values around 25.1 and 32.2. The peaks of vaterite were found for $2 \theta$ values around $21^{\circ}, 24.9^{\circ}, 27^{\circ}$, and 32.8. However, brushite peaks did not appear on the XRD pattern, attesting that the DCPD has entirely reacted during the setting reaction. The XRD patterns obtained for the composites CPC-BG25 and CPC-BG25-Alg5 perfectly matched with that of the reference compound (CPC); thus, the main peaks of the nanocrystalline apatite and 
residual vaterite were indexed and no additional phases were detected after the incorporation of bioglass and association with alginate. Moreover, the amorphous halo characterizing the BG structure did not appear in the XRD patterns of formulated cements, and it could be present under the wide peak of the nanocrystallized apatite.

It is obvious that by the introduction of $\mathrm{BG}$ into the $\mathrm{CPC}$ matrix, a relatively higher intensity of apatite lines at 32.2 and 25.9 is noticed taking the vaterite residue lines as reference. A reverse trend was detected by introducing alginate; the relative intensity of apatite decreased compared to CPC-BG25. This could be due to the inhibition of ionic diffusion, delaying the apatite formation because of the viscosity of the pastes in the presence of alginate hydrogel. The possible formation of calcium alginate, which consumes a part of calcium ions, could also account for the lowering of apatite relative intensity. It has been reported that the association of sodium alginate with TTCPDCPA-based cement, and a CPC based on $\alpha$-TCP, leads to a possible formation of calcium alginate through the ionic exchange of sodium by calcium following the equation $3[38,39]$ :

$$
2 \mathrm{Na}-\mathrm{Alg}+\mathrm{Ca}^{2+} \rightarrow \mathrm{Ca}-\mathrm{Alg}_{2}+2 \mathrm{Na}^{+}
$$

\section{Fig. 2}

FTIR spectra of reactive powders and formulated materials are depicted in Fig. 3. The spectra are normalized and the $\mathrm{v} 3 \mathrm{PO}_{4}$ band (around $1050 \mathrm{~cm}^{1}$ ) was used as the reference band when available.

The FTIR spectrum of DCPD displayed all the bands characteristic of phosphates at $526,577,790,872,984,1060,1132$ and $1215 \mathrm{~cm}^{-1}$ as well as water molecules at 1650 , 1727, 3166, 3280, 3490, and $3543 \mathrm{~cm}^{-1}$ [40]. The vaterite FTIR spectrum exhibited a symmetric carbonate stretching vibration $(v 1)$ at $1080 \mathrm{~cm}^{-1}$, a carbonate out-of-plane 
bending vibration ( $v 2)$ at $860 \mathrm{~cm}^{-1}$, an asymmetric carbonate stretching vibration (v3) between 1403 and $1492 \mathrm{~cm}^{-1}$, and a carbonate deformation vibration (v4) at $745 \mathrm{~cm}^{-1}$ [29]. The sodium alginate revealed characteristic bands assigned to $\mathrm{OH}, \mathrm{COO}$ antisymmetric, $\mathrm{COO}$ symmetric, $\mathrm{C}-\mathrm{O}(\mathrm{H})$, and $\mathrm{C}-\mathrm{O}-\mathrm{C}$ vibrational modes, respectively, at $3300,1598,1410,1300$, and $1084 \mathrm{~cm}^{-1}$ [41].

The FTIR spectrum of CPC used as reference cement showed a wide and intense band in the domain $3000-3400 \mathrm{~cm}^{-1}$ indicating the presence of adsorbed water (Fig. 3). The bands in $1000-1150 \mathrm{~cm}^{-1}$ and $550-650 \mathrm{~cm}^{-1}$ regions are assigned, respectively, to the $v 3$ and $v 4$ vibration modes of the phosphate groups [42]. Furthermore, bands corresponding to residual vaterite and attributed to the $v 3$ and $v 2$ vibrations of carbonate species were observed in the region of $1400-1500 \mathrm{~cm}^{-1}$ and at $876 \mathrm{~cm}^{-1}$, respectively. The typical bands of carbonates with low intensity appear also in this domain for the apatite cement. It can also be noted that the brushite bands are no longer apparent in the CPC spectrum, indicating that DCPD has been completely consumed during the setting reaction.

The spectra of CPC-BG25 and CPC-BG25-Alg5 display a similar feature to the CPC spectrum, in agreement with the XRD data (Fig. 3). In addition to the bands of carbonate apatite and residual vaterite, new bands and spectral modifications occurred in the spectra of the composites. For instance, a low-intensity band attributed to the bending of Si-O-Si of the bioactive glass (BG) was identified at $470 \mathrm{~cm}^{-1}$ with a slight displacement from $525 \mathrm{~cm}^{-1}$ for pure $\mathrm{BG}$, suggesting the existence of interactions between the components of glass, brushite, and vaterite.

The presence of bioactive glass in the composites CPC-BG25 and CPC-BG25-Alg5 led to a decrease in the intensity and an increase in the $\mathrm{CO}_{3}$ bandwidth located in the range $800-850 \mathrm{~cm}^{-1}$, compared to the reference cement CPC. This modification could be due to the overlap between the $\mathrm{CO}_{3}$ band and the $\mathrm{Si}-\mathrm{O}-\mathrm{Si}$ wide band of glass material. The bands typical of sodium alginate were not detected in the spectrum of CPC-BG25-Alg5; 
this could be due to the low amount of product used and/or the overlapping with the bands of vaterite and apatite.

\section{Fig. 3}

\subsection{Morphological examination}

Fig. 4 regroups SEM images of the starting materials (vaterite, DCPD, bioactive glass, and sodium alginate), as well as the SEM micrographs and elemental compositions of the formulated cements (CPC, CPC-BG25, and CPC-BG25-Alg5). The vaterite particles appear as agglomerated polycrystalline spheres (between $0.5-3 \mu \mathrm{m}$ ) (Fig. 4A). The SEM image of the brushite crystals depicts platelet-shaped aggregates (Fig. 4B), whereas the bioactive glass consists of large, block-shaped particles (Fig. 4C). The CPC SEM image (Fig. 4E) reveals the presence of macropores distributed nonhomogeneously, probably originating from the formation of carbon dioxide $\left(\mathrm{CO}_{2}\right)$ bubbles during the setting chemical reaction, resulting in the formation of apatite from brushite and vaterite, as shown in the following reaction (2):

$$
4 \mathrm{CaCO}_{3}+6 \mathrm{CaHPO}_{4} \cdot 2 \mathrm{H}_{2} \mathrm{O} \rightarrow \mathrm{Ca}_{10}\left(\mathrm{PO}_{4}\right)_{6}(\mathrm{OH})_{2}+4 \mathrm{CO}_{2}+14 \mathrm{H}_{2} \mathrm{O}
$$

The given formula corresponds to the stoichiometric apatite, but this is far from being the case for the prepared cements.

The micrographs of CPC (Fig. 4F and Fig. 4G) show densely agglomerated spherical particles having lentil-like shapes with an average particle size of 2-3 $\mu \mathrm{m}$ attributed to the residual vaterite, which are enclosed by small crystals of fine plate-like morphology characteristic of nanocrystalline apatite. The absence of thin platelets specific to DCPD in the micrographs implies its total reaction with vaterite after $48 \mathrm{~h}$. The morphology of the hardened CPC-BG25 cement appeared to be more compact than the CPC surface (Fig. 4H). Moreover, the SEM micrographs of CPC-BG25 indicated the presence of 
glass material characterized by large block-like shapes (pink arrows) in intimate contact with residual vaterite (blue arrows) (Fig. 4J). The formation of the tiny needle-like crystals (yellow arrows) surrounding residual vaterite and bioactive glass (Fig. 4J) is attributed to the newly formed nanocrystalline apatite.

The surface morphology of CPC-BG25-Alg5 (Fig. 4K, 4L, and 4M) indicated the presence of glass blocks, residual vaterite, and the formed apatite. The composite CPCBG25-Alg5 exhibited the densest microstructure with the almost total disappearance of pores on the surface. However, the polymeric phase is not distinguished, possibly due to the smaller content of alginate hydrogel compared to the powder phase of cement.

The EDS analysis of the reference cement (CPC) shows the presence of $\mathrm{Ca}, \mathrm{P}, \mathrm{O}$ element peaks attributed to the presence of apatite and vaterite phases. The EDS spectrum of CPC-BG25 states the presence of additional elements, such as $\mathrm{Na}$ and $\mathrm{Si}$, characterizing the presence of bioactive glass in the CPC matrix as noticed in the SEM micrographs. The elements $\mathrm{Ca}, \mathrm{P}, \mathrm{O}, \mathrm{Na}$, and $\mathrm{Si}$ are also present in the spectrum of CPC-BG25-Alg5 composite evidencing the presence of the apatite, vaterite, and bioactive glass phases. Moreover, the peak intensity of $\mathrm{Na}$ and $\mathrm{C}$ slightly increased due to the presence of alginate polymer $\left(\mathrm{C}_{6} \mathrm{H}_{7} \mathrm{NaO}_{6}\right)$.

\subsection{Porosity measurements}

The porosity of hardened samples was determined through Mercury Intrusion Porosimetry (MIP). The pore volume values of the composites CPC, CPC-BG25, and CPC-BG25-Alg5 as representative samples are summarized in Table 1. The CPC sample presented a porosity of $856 \mathrm{~mm}^{3} / \mathrm{g}$, which decreased by approximately $41 \%$ for CPC-BG25 cement to reach a value of $504 \mathrm{~mm}^{3} / \mathrm{g}$. The addition of $5 \%$ of sodium alginate to the CPC-BG25 matrix induced a significant decrease of the porosity volume to a value of $362 \mathrm{~mm}^{3} / \mathrm{g}$, in agreement with the densest microstructure noticed by SEM for the composite CPC-BG25-Alg5. The decrease of the porosity of the CPC-BG25 
composite could be explained by the cross-linked network between the bioactive glass and the formed apatite, providing a dense structure of the cements. The coexistence of glass and alginate leads to a decrease in porosity, which could be explained by the viscosity of the hydrogel enriching the liquid phase with sodium and consequently forming a more rigid and compact network with silica.

Fig. 4

Table 2. Porosity values for CPC, CPC-BG25, and CPC-BG25-Alg5.

\begin{tabular}{l|c|c|c}
\hline Materials & CPC & CPC-BG25 & CPC-BG25-Alg5 \\
\hline Porosity volume & 856 & 504 & 362 \\
$\left(\mathbf{m m}^{3} / \mathbf{g}\right)$ & & & \\
\hline
\end{tabular}

\subsection{Self-setting properties}

\subsubsection{Kinetics of setting}

The setting reaction of prepared materials was assessed by XRD $\left(10-55^{\circ}\right)$ and FTIR spectroscopy (in the range of $900-1270 \mathrm{~cm}^{-1}$ ) after several times of reaction to monitor the apatite formation in the formulated composites. The setting kinetics were evaluated through the evolution of FTIR bands and XRD peaks of the brushite as the limiting reagent, and apatite as the newly formed phase. The evolution of XRD patterns of CPCBG25, CPC-BG25-Alg5, and the reference cement (CPC), as a function of time $(2,4,6$, 24, and 48h), is illustrated in Fig. 5. After 2 hours of contact, only peaks of DCPD and vaterite were observed for the examined materials. As the reaction proceeds, the DCPD and vaterite peak intensities diminished, while apatite peaks appeared and increased in intensity. The CPC XRD pattern revealed that the DCPD intense peaks noticed around $11.7^{\circ}, 23.5^{\circ}$, and $29.3^{\circ}$ disappeared after $48 \mathrm{~h}$ of reaction, leading to the formation of the 
apatitic phase. However, significant differences occurred for the composites only 4 hours after the setting reaction began. Thus, the XRD pattern of CPC-BG25 exhibited new peaks mainly at $26.0^{\circ}$ and $32.7^{\circ}$ assigned to the apatite phase, while no peak characteristics of DCPD were recorded. Besides, the XRD pattern of CPC-BG25-Alg5 does not display peaks typical of brushite after $6 \mathrm{~h}$ of reaction, suggesting that the presence of sodium alginate $(5 \%)$ affected the setting kinetics.

The obtained results by FTIR analysis are consistent with the XRD data (Fig. 5). As can be seen from the FTIR spectrum of CPC, the setting reaction is incomplete after $24 \mathrm{~h}$ as confirmed by the presence of hydrogenophosphate groups (at 985 and $1132 \mathrm{~cm}^{-1}$ ) typical of DCPD and the total disappearance of brushite for 48h. However, these species disappeared from the FTIR spectrum of composites CPC-BG25 and CPC-BG25-Alg5 after $4 \mathrm{~h}$ and $6 \mathrm{~h}$ of reaction, respectively.

The XRD and FTIR results are in accordance and prove that the incorporation of bioactive glass within CPC matrix accelerates the apatite formation, implying that bioglass contributes to the setting reaction of the CPC-BG25 cement. This could be related to the supersaturation of the liquid phase caused by the rapid dissolution of the glass, resulting in a high content of active electrolyte species (typically calcium and phosphate ions from the glass as well as ions released from brushite and vaterite dissolution), favorable to the nucleation of apatite crystals [43].

To monitor the apatite formation during the setting reaction for the prepared cements, the XRD peak intensity ratio between apatite $\left(26^{\circ}\right)$ and vaterite $\left(25.2^{\circ}\right)$ has been determined. The apatite/vaterite intensity ratio $\left(\mathrm{I}_{\mathrm{Ap}} / \mathrm{I}_{\mathrm{Vat}}\right)$ increased as a function of incubation time for all formulated compounds (Fig. 6). The CPC-BG25 cement exhibited the highest $\mathrm{I}_{\mathrm{Ap}} / \mathrm{I}_{\mathrm{Vat}}$ ratio during the first hours of incubation in comparison with CPC and CPC-BG25-Alg5 compounds, suggesting a faster setting reaction and thus a rapid formation of apatite. 
Fig. 5

Fig. 6

The significant increase of the intensity ratio for the CPC-BG25 specimen during the first incubation time revealed that the reaction still occurs after 4 hours of contact, which is manifested in XRD patterns by the growth of the apatite peaks even after $4 \mathrm{~h}$. This could be attributed to the presence of bioactive glass, which serves as a source of phosphate and calcium. However, the addition of sodium alginate (5 wt $\%$ ) slowed down the setting kinetics compared to CPC-BG25 cement, but it still remains faster compared to the reference cement (CPC). After $48 \mathrm{~h}$ of contact, the CPC-BG25-Alg5 exhibits the lowest intensity ratio attesting that the amount of the newly formed apatite is the lowest compared to $\mathrm{CPC}$ and $\mathrm{CPC}-\mathrm{BG} 25$ cements. This result could be explained by the reduction of the dissolution rate of reactive powders because of the viscosity of the alginate solution. The formation of calcium alginate as a competitive reaction in the immobilization of calcium ions has also to be considered to explain the delay of the apatite formation.

\subsubsection{Setting time measurement}

Table 3 illustrates the evolution of initial and final setting times for the reference cement CPC compared to the cement containing various amounts of bioactive glass CPC-BGx $(\mathrm{x}=10,15$, and $25 \%)$ and the cement CPC-BG25 associated with alginate at different rates CPC-BG25-Algy $(y=1,3$, and 5\%). The addition of BG to the reference cement CPC reduced the setting times and this effect is $\mathrm{BG}$ dose-dependent. The initial setting time decreased from $75 \pm 3$ min to $42 \pm 3$ min when the weight ratio of BG varied from $0 \%$ up to $25 \%$. Moreover, the final setting time diminished from a value of $119 \pm 5 \mathrm{~min}$ 
for CPC to $65 \pm 3 \mathrm{~min}$ for CPC-BG25 (Table 3). This effect could be attributed to the increase of $\mathrm{Ca}^{2+}$ released from the bioactive glass matrix, which could be involved in the reprecipitation process, leading to a rapid setting reaction. Similar observations have been reported for a silicate-based nano-bioactive glass associated with CPC cement [44]. In contrast to the obtained results, it has been reported that the incorporation of bioactive glass $45 \mathrm{~S} 5$ increases the setting time for CPC composed of $\alpha$-tricalcium phosphate $(\alpha-\mathrm{TCP})$, dicalcium phosphate anhydrous (DCPA), and hydroxyapatite (HA) [45], and for CPC based on tetracalcium phosphate (TTCP) and dicalcium phosphate anhydrous (DCPA) [28].

On the other hand, the increase of the polymeric phase (Alg) in the range 0-5\% delayed the initial setting time from $42 \pm 3$ min for CPC-BG25 to $73 \pm 3$ min for CPC-BG25Alg5. For the final setting time, the duration was extended from $65 \pm 3$ min for the reference compound CPC-BG25 up to $124 \pm 3$ min for the specimen CPC-BG25-Alg5 containing the highest amount of polymer $(5 \mathrm{wt} \%)$. The final setting time was also affected by the increase of Alg content from $1 \mathrm{wt} \%$ to $5 \mathrm{wt} \%$ from a value of 83 to 121 min. The association of CPC-BG25 with sodium alginate polymer involved a delaying effect of the setting time. This effect can be related to the formation of calcium alginate which affects the primary nucleation, interfering with the precipitation of apatite and delaying the setting reaction. Such effect has been reported for CPC based on monocalcium phosphate monohydrate $(\mathrm{MCPM})$ - calcium carbonate $\left(\mathrm{CaCO}_{3}\right)$ for which an increase of the initial setting time from $8 \pm 1 \mathrm{~min}$ to $12 \pm 1 \mathrm{~min}$ occurred in the presence of sodium alginate [46]. However, an opposite tendency was noticed when alginate was combined with chitosan and then associated with a calcium phosphate cement-based on $\beta$-TCP and MCPM powders [47].

The analysis of setting properties of the formulated materials in the present work stated that the association of glassy material with calcium phosphate cement remarkably 
decreased the setting reaction. The effect could be mainly attributed to the fast kinetics regarding the nucleation/formation of apatite in the presence of bioglass.

Table 3: Initial $\left(\mathrm{t}_{\mathrm{i}}\right)$ and final $\left(\mathrm{t}_{\mathrm{f}}\right)$ setting times of prepared cements and composites.

\begin{tabular}{lcc}
\hline Sample & $\mathbf{t}_{\mathbf{i}}(\mathbf{m i n})$ & $\mathbf{t}_{\mathbf{f}}(\mathbf{m i n})$ \\
\hline CPC & $75 \pm 3$ & $119 \pm 5$ \\
\hline CPC-BG10 & $61 \pm 2$ & $88 \pm 4$ \\
\hline CPC-BG15 & $53 \pm 3$ & $82 \pm 3$ \\
\hline CPC-BG25 & $42 \pm 3$ & $65 \pm 3$ \\
\hline CPC-BG25-Alg1 & $50 \pm 3$ & $83 \pm 4$ \\
\hline CPC-BG25-Alg3 & $62 \pm 3$ & $105 \pm 2$ \\
\hline CPC-BG25-Alg5 & $73 \pm 3$ & $121 \pm 4$
\end{tabular}

\subsection{Injectability and cohesion tests}

The cohesion property was assessed for the reference cement (CPC) and the composites cements (CPC-BG25, and CPC-BG25-Alg5) through a visual examination of the aspect of the injected pastes into $\mathrm{NaCl}$ solution $(0.9 \% \mathrm{w} / \mathrm{w})$ over different periods of time (Fig. 7). As can be seen, CPC and CPC-BG25 samples disintegrated when injected into the solution because of the extrusion of a liquid-rich paste, thus facilitating the penetration of $\mathrm{NaCl}$ solution in the paste and then its fragmentation. However, the composite paste loaded with $5 \%$ alginate retains its shape even after 24 hours of immersion, and no segregation was noticed. This attests that the association of alginate with the cement significantly enhanced the cohesion property. This could be attributed to the penetration of the alginate hydrogel between the particles, leading to the rise of the viscosity of the pastes, which prevents their demixing and promotes their cohesion. These observations are in line with the amelioration of rheological properties of CPC 
formulated with the polymers-containing liquid phase, such as hydroxypropyl methylcellulose (HPMC), chitosan, sodium alginate; due to the increase of the CPC paste viscosity, which could prevent penetration of the fluid between the CPC powder components [48].

Injectability measurements performed on the formulated self-setting materials are presented in Figure 8. The results obtained attested that the extrusion behavior of the reference material is enhanced when mixed with the glass component. Thus, the injectability rate of CPC raised from $34 \%$ to the values of 44,50 , and $62 \%$ as the amount of glass incorporated was 10,15 , and $25 \mathrm{wt} \%$, respectively. The improvement of the injectability by the addition of $\mathrm{BG}$ could be attributed to the calcium silica hydrate gel formed by the reaction of BG with water, which increased the viscosity of the setting liquid. Moreover, particle size is a key parameter for the improvement of rheological properties. Indeed, the smaller particle sizes of brushite and vaterite compared to bioglass, absorb a higher volume of water, leading to a reduction in particle spacing requiring higher extrusion forces and thus reduced injection power. However, the addition of BG with a coarse particle size (between 100-200 $\mu \mathrm{m}$ ) compared to DCPD (in the range of 5-20 $\mu \mathrm{m}$ ) and $\mathrm{CaCO}_{3}$ (between $0.5-3 \mu \mathrm{m}$ ) decreased the amount of water absorbed and thus decreased the extrusion force and then enhanced the injectability of the paste. A similar result was found and attested that the addition of glass beads with a diameter of $156 \mu \mathrm{m}$ to a $\beta$-TCP-based paste improved the injectability [49]. The same was observed for calcium phosphate cement-based on monocalcium phosphate hydrate and $\beta$-tricalcium phosphate (MCPM- $\beta$-TCP), showing that the pastes extrusion behavior was strongly affected by the particle size of MCPH [50]. The addition of bioglass (BG) enhanced the injectability of CPC but it is not yet fully injectable due to the blocking of part of the cement paste in the syringe (characteristic of the presence of a filter pressing phenomenon during paste extrusion). 
The lower injectability observed for CPC and CPC-BG may be related to the low cohesion of their corresponding pastes causing the phase-separation. This phenomenon is characterized by the migration of the liquid phase through the paste to regions of lower pressure, i.e., out of the extruder, resulting in the injection of a liquid-rich paste; thus, limiting the injectability.

To remedy this phenomenon, the combination of sodium alginate hydrogel with the CPC-BG25 matrix has been explored. Thus, the addition of different amounts of sodium alginate, up to $5 \%$, to the CPC-BG25, significantly enhanced the injectability with a maximum value of $98 \%$ related to CPC-BG25-Alg5 composite. The improvement of injectability could be linked to the lubricating nature of the hydrogel, where solid particles slide on each other making the paste easier to extrude and therefore improving the injection of cement pastes. Moreover, this improvement is probably also due to the good cohesion between the cement components in the presence of Alg. The presence of the Alg hydrogel prevents the migration of the liquid phase through the paste and consequently, it eliminates the phase separation phenomenon which is responsible for the low injectability of the CPC and CPC-BG cement. Similarly, the strontiumsubstituted $\alpha$-TCP cement enriched with alginate exhibited improved rheological properties, without cement fragmentation [51].

\section{Fig. 7}

\subsection{Compressive strength}

The compressive strength measured for the prepared composites with different content of bioglass and alginate is presented in Figure 9. On one hand, the increase of BG amount from 10 to $25 \mathrm{wt} \%$ enhanced the compressive strength from a value of $4.0 \mathrm{MPa}$ for $\mathrm{CPC}$ to $5.5 \mathrm{MPa}$ for $\mathrm{CPC}-\mathrm{BG} 25$; as a consequence of the decrease of porosity upon 
addition of bioglass to the CPC matrix as shown in Table 2. On the other hand, the addition of sodium alginate $(1,3$, and $5 \mathrm{wt} \%)$ increased the compressive strength and reached a maximum value of 7.2 $\mathrm{MPa}$ for the CPC-BG25-Alg5 composite. The increase of the mechanical strength through the combination of both BG and Alg with CPC is in good agreement with the decrease of pore volume as measured by $\mathrm{Hg}$ porosimetry (Table 2) from $856 \mathrm{~mm}^{3} / \mathrm{g}$ for CPC cement to 504 and $362 \mathrm{~mm}^{3} / \mathrm{g}$ for CPC-BG25 and CPC-BG25-Alg5, respectively. The effect of the alginate hydrogel in the case of CPCBG25-Alg5 could be related to the enhancement of the cohesion property of the cement leading to a dense structure as observed by SEM micrographs (Fig. 4K) and attested by porosity values.

\section{Fig. 8}

These findings are consistent with those reported in the literature. In general, the compressive strength of CPCs depends on the amount of glassy materials and polymers. For instance, the association of $30 \%$ of bioactive glass $45 \mathrm{~S} 5$ with CPC composed of TTCP-DCPA caused an increase of the compressive strength from $11 \mathrm{MPa}$ for CPC to $15 \mathrm{MPa}$ [28]. Zhou et al. have suggested that the bioactive glass cement structure can be cross-linked by the formed apatite to provide a compact structure, enhancing the compressive strength of cement[52]. Regarding the polymer addition, it has been reported that the incorporation of carboxymethylcellulose with $\mathrm{DCPD}-\mathrm{CaCO}_{3}$ cement significantly improved the compressive strength of formulated composites [19]. Bigi et al. stated that the addition of gelatin in an $\alpha$-TCP cement increases the compressive strength, due to the decrease in sample porosity [53]. Moreover, sodium alginate notably improved the mechanical strength of the cement-based on the Sr-substituted $\alpha \mathrm{TCP}$ phase and this was attributed to a crack-bridging effect provided by alginate [24]. 
The compressive strength values of the prepared specimens showed clear enhancement with the increased amount of $\mathrm{BG}$ and $\mathrm{Alg}$, going from a value of $4.0 \mathrm{MPa}$ for $\mathrm{CPC}$ to 5.5 MPa for CPC-MB25 cement, and reaching a value of 7.2 MPa for the CPC-MB25Alg5 composite. These results are consistent with the porosity measurements, and microstructure examination.

Overall, the synergistic effect of combining bioactive glass and sodium alginate hydrogel on the physical properties of calcium phosphate cement (CPC) led to the design of a novel composite cement CPC-BG-Alg with promising properties in terms of setting reaction, injectability, cohesion, and compressive strength, for use as a biomaterial. However, the extended setting time of the elaborated composite in the presence of alginate can be regulated by the addition of an appropriate setting accelerator. This will be the purpose of the forthcoming research work for publication.

\section{Fig. 9}

\section{Conclusion}

A novel composite cement was developed by combining bioactive glass $46 \mathrm{~S} 6$ and sodium alginate hydrogel with CPC cement to improve its physical features. The incorporation of $25 \mathrm{wt} \%$ of bioactive glass into the CPC matrix has significantly accelerated the setting reaction and time, and slightly increased the injectability of the resulting cement. Moreover, a cement with higher mechanical strength, better cohesion, and injectability properties was obtained by the addition of only $5 \mathrm{wt} \%$ of sodium alginate. However, the setting time was prolonged as a trade-off. The results highlight the effective role of the bioactive glass $46 \mathrm{~S} 6$ in the improvement of CPC properties, proving that the $\mathrm{BG}$ participates in the setting reaction as a reactive material. 
Furthermore, alginate hydrogel plays a key role as an additive for the improvement of rheological and mechanical properties of CPC.

Future studies will focus on understanding the mechanism by which the CPC matrix is associated with $46 \mathrm{~S} 6$ bioactive glass, as well as improving the setting time and enhancing the composite system's mechanical strength.

\section{Acknowledgment}

This work was done with the financial support of the OCP group (Morocco) through the APPHOS Program (project ID: MAT-BAR-01/2017). The authors further thank the Center of Analysis and Characterization (CAC) of Cadi Ayyad University. We would like also to thank especially Dr. Rachid Boulif and Dr. Hicham Hassoune for porosity measurements and Pr Rachid HAKKOU for mechanical properties.

\section{Conflicts of interest}

The authors declare no conflict of interest 


\section{References}

[1] A. Diez-Escudero, M. Espanol, M.P. Ginebra, Synthetic bone graft substitutes: Calcium-based biomaterials, Elsevier Ltd., 2019. https://doi.org/10.1016/B978-008-102478-2.00006-4.

[2] W. Wang, K.W.K. Yeung, Bone grafts and biomaterials substitutes for bone defect repair: A review, Bioact. Mater. 2 (2017) 224-247. https://doi.org/10.1016/j.bioactmat.2017.05.007.

[3] R. Dimitriou, G.I. Mataliotakis, A.G. Angoules, N.K. Kanakaris, P. V. Giannoudis, Complications following autologous bone graft harvesting from the iliac crest and using the RIA: A systematic review, Injury. 42 (2011) S3-S15. https://doi.org/10.1016/j.injury.2011.06.015.

[4] W. Habraken, P. Habibovic, M. Epple, M. Bohner, Calcium phosphates in biomedical applications: Materials for the future?, Mater. Today. 19 (2016) 6987. https://doi.org/10.1016/j.mattod.2015.10.008.

[5] A.M. Yousefi, A review of calcium phosphate cements and acrylic bone cements as injectable materials for bone repair and implant fixation, J. Appl. Biomater. Funct. Mater. 17 (2019). https://doi.org/10.1177/2280800019872594.

[6] M.-P. Ginebra, E.B. Montufar, Cements as bone repair materials, Second Edi, Elsevier Ltd, 2019. https://doi.org/10.1016/b978-0-08-102451-5.00009-3.

[7] C. Liu, H. He, Developments and Applications of Calcium Phosphate Bone Cements, 2018. https://doi.org/10.1007/978-981-10-5975-9.

[8] R. O’Neill, H.O. McCarthy, E.B. Montufar, M.P. Ginebra, D.I. Wilson, A. Lennon, N. Dunne, Critical review: Injectability of calcium phosphate pastes and cements, $\quad$ Acta $\quad$ Biomater. $\quad 50 \quad$ (2017) 1-19. https://doi.org/10.1016/j.actbio.2016.11.019.

[9] R.A. Perez, H.W. Kim, M.P. Ginebra, Polymeric additives to enhance the 
functional properties of calcium phosphate cements, J. Tissue Eng. 3 (2012) 120. https://doi.org/10.1177/2041731412439555.

[10] A. V Boehm, S. Meininger, A. Tesch, U. Gbureck, F.A. Muller, The Mechanical Properties of Biocompatible Apatite Bone Cement Reinforced with Chemically Activated Carbon Fibers, Mater. 11 (2018). https://doi.org/10.3390/ma11020192.

[11] H. Guo, J. Wei, C.S. Liu, Development of a degradable cement of calcium phosphate and calcium sulfate composite for bone reconstruction, Biomed. Mater. 1 (2006) 193-197. https://doi.org/10.1088/1748-6041/1/4/003.

[12] M.L. Hasan, B. Kim, A.R. Padalhin, O. Faruq, T. Sultana, B.T. Lee, In vitro and in vivo evaluation of bioglass microspheres incorporated brushite cement for bone regeneration, Mater. Sci. $\quad$ Eng. C. $103 \quad$ (2019) 109775. https://doi.org/10.1016/j.msec.2019.109775.

[13] A.C.M. Renno, F.C.J. Van De Watering, M.R. Nejadnik, M.C. Crovace, E.D. Zanotto, J.G.C. Wolke, J.A. Jansen, J.J.J.P. Van Den Beucken, Incorporation of bioactive glass in calcium phosphate cement: An evaluation, Acta Biomater. 9 (2013) 5728-5739. https://doi.org/10.1016/j.actbio.2012.11.009.

[14] S. V Dorozhkin, Self-setting calcium orthophosphate $\left(\mathrm{CaPO}_{4}\right)$ formulations and their biomedical applications, Adv. Nano-Bio-Materals Devices. 3 (2019) 321421.

[15] F. Ridi, I. Meazzini, B. Castroflorio, M. Bonini, D. Berti, P. Baglioni, Functional calcium phosphate composites in nanomedicine, Adv. Colloid Interface Sci. 244 (2017) 281-295. https://doi.org/10.1016/j.cis.2016.03.006.

[16] C.H. Fang, Y.W. Lin, J.S. Sun, F.H. Lin, The chitosan/tri-calcium phosphate biocomposite bone cement promotes better osteo-integration: an in vitro and in vivo study, J Orthop Surg Res. 14 (2019) 162. https://doi.org/10.1186/s13018-019$1201-2$. 
[17] Y. Li, Y.M. Liu, T. Fu, B. Li, [Influence of gelatin particle size and gelatin/calcium phosphate cement ratio on repairing potency of composite artificial bone material], Zhejiang Da Xue Xue Bao Yi Xue Ban. 44 (2015) 293300. https://www.ncbi.nlm.nih.gov/pubmed/26350010.

[18] Z.Q. Zhou, D.P. Ye, W.G. Liang, B. Wang, Z.Z. Zhu, Preparation and characterization of a novel injectable strontium-containing calcium phosphate cement with collagen, Chin J Traumatol. 18 (2015) 33-38. https://doi.org/10.1016/j.cjtee.2014.08.001.

[19] S. Jacquart, D. Poquillon, G. Dechambre, S. Cazalbou, C. Rey, C. Combes, Mechanical properties of self-setting composites: influence of the carboxymethylcellulose content and hydration state, J. Mater. Sci. 51 (2016) 4296-4305. https://doi.org/10.1007/s10853-016-9739-4.

[20] J.H. Park, E.J. Lee, J.C. Knowles, H.W. Kim, Preparation of in situ hardening composite microcarriers: calcium phosphate cement combined with alginate for bone regeneration, J Biomater Appl. 28 (2014) 1079-1084. https://doi.org/10.1177/0885328213496486.

[21] P. Gentile, V. Chiono, I. Carmagnola, P. V Hatton, An overview of poly(lacticco-glycolic) acid (PLGA)-based biomaterials for bone tissue engineering, Int $\mathbf{J}$ Mol Sci. 15 (2014) 3640-3659. https://doi.org/10.3390/ijms15033640.

[22] L. Vojtova, L. Michlovska, K. Valova, M. Zboncak, M. Trunec, K. Castkova, M. Krticka, V. Pavlinakova, P. Polacek, M. Dzurov, V. Lukasova, M. Rampichova, T. Suchy, R. Sedlacek, M.P. Ginebra, E.B. Montufar, The Effect of the Thermosensitive Biodegradable PLGA(-)PEG(-)PLGA Copolymer on the Rheological, Structural and Mechanical Properties of Thixotropic Self-Hardening Tricalcium Phosphate Cement, Int J Mol Sci. 20 (2019). https://doi.org/10.3390/ijms20020391. 
[23] G.S. Lee, J.H. Park, U.S. Shin, H.W. Kim, Direct deposited porous scaffolds of calcium phosphate cement with alginate for drug delivery and bone tissue engineering, Acta Biomater. $7 \quad$ (2011) 3178-3186. https://doi.org/10.1016/j.actbio.2011.04.008.

[24] S. Sprio, M. Dapporto, M. Montesi, S. Panseri, W. Lattanzi, E. Pola, G. Logroscino, A. Tampieri, Novel osteointegrative sr-substituted apatitic cements enriched with Alginate, Materials (Basel). 9 (2016) 1-17. https://doi.org/10.3390/ma9090763.

[25] F. Baino, S. Hamzehlou, S. Kargozar, Bioactive Glasses: Where Are We and Where Are We Going?, J Funct Biomater. 9 (2018). https://doi.org/10.3390/jfb9010025.

[26] L.L. Hench, J.R. Jones, Bioactive Glasses: Frontiers and Challenges, Front Bioeng Biotechnol. 3 (2015) 194. https://doi.org/10.3389/fbioe.2015.00194.

[27] B. San Miguel, R. Kriauciunas, S. Tosatti, M. Ehrbar, C. Ghayor, M. Textor, F.E. Weber, Enhanced osteoblastic activity and bone regeneration using surfacemodified porous bioactive glass scaffolds, J. Biomed. Mater. Res. - Part A. 94 (2010) 1023-1033. https://doi.org/10.1002/jbm.a.32773.

[28] L. Yu, Y. Li, K. Zhao, Y. Tang, Z. Cheng, J. Chen, Y. Zang, J. Wu, L. Kong, S. Liu, W. Lei, Z. Wu, A novel injectable calcium phosphate cement-bioactive glass composite for bone regeneration, PLoS One. 8 (2013) e62570. https://doi.org/10.1371/journal.pone.0062570.

[29] C. Combes, R. Bareille, C. \%J J. of B.M.R.P.A.A.O.J. of T.S. for B. Rey The Japanese Society for Biomaterials, T.A.S. for Biomaterials, the K.S. for Biomaterials, Calcium carbonate-calcium phosphate mixed cement compositions for bone reconstruction, 79 (2006) 318-328.

[30] S. Jacquart, R. Siadous, C. Henocq-Pigasse, R. Bareille, C. Roques, C. Rey, C. 
Combes, Composition and properties of silver-containing calcium carbonatecalcium phosphate bone cement, J. Mater. Sci. Mater. Med. 24 (2013) 26652675. https://doi.org/10.1007/s10856-013-5014-2.

[31] H. Oudadesse, E. Dietrich, Y.L. Gal, P. Pellen, B. Bureau, A.A. Mostafa, G. Cathelineau, Apatite forming ability and cytocompatibility of pure and Zn-doped bioactive glasses, Biomed Mater. 6 (2011) 35006. https://doi.org/10.1088/17486041/6/3/035006.

[32] H. Shi, X. Ye, F. He, J. Ye, Improving osteogenesis of calcium phosphate bone cement by incorporating with lysine: An in vitro study, Colloids Surf B Biointerfaces. $462-469$. https://doi.org/10.1016/j.colsurfb.2019.02.034.

[33] W.T. Coelho, J.M. Fernandes, R.S. Vieira, M.B. Thurmer, L.A. Santos, Effect on mechanical strength of tricalcium phosphate cement by additions of sodium alginate, Mater. Sci. Forum. 727-728 (2012) 1181-1186. https://doi.org/10.4028/www.scientific.net/MSF.727-728.1181.

[34] P. Sepulveda, J.R. Jones, L.L. Hench, In vitro dissolution of melt-derived 45S5 and sol-gel derived 58S bioactive glasses, J. Biomed. Mater. Res. 61 (2002) 301311. https://doi.org/10.1002/jbm.10207.

[35] J. Hum, A.R. Boccaccini, Collagen as coating material for 45S5 bioactive glassbased scaffolds for bone tissue engineering, Int. J. Mol. Sci. 19 (2018). https://doi.org/10.3390/ijms19061807.

[36] H. Zheng, J. Yang, S. Han, The synthesis and characteristics of sodium alginate/graphene oxide composite films crosslinked with multivalent cations, J. Appl. Polym. Sci. 133 (2016) 1-7. https://doi.org/10.1002/app.43616.

[37] H. Noukrati, S. Cazalbou, I. Demnati, C. Rey, A. Barroug, C. Combes, Injectability, microstructure and release properties of sodium fusidate-loaded 
apatitic cement as a local drug-delivery system, Mater. Sci. Eng. C. (2016). https://doi.org/10.1016/j.msec.2015.09.070.

[38] G.S. Lee, J.H. Park, J.E. Won, U.S. Shin, H.W. Kim, Alginate combined calcium phosphate cements: Mechanical properties and in vitro rat bone marrow stromal cell responses, J. Mater. Sci. Mater. Med. 22 (2011) 1257-1268. https://doi.org/10.1007/s10856-011-4296-5.

[39] K. Ishikawa, Y. Miyamoto, M. Kon, M. Nagayama, K. Asaoka, Non-decay type fast-setting calcium phosphate cement: composite with sodium alginate, Biomaterials. 16 (1995) 527-532. https://doi.org/10.1016/0142-9612(95)91125-I.

[40] M. Sayahi, J. Santos, H. El-Feki, C. Charvillat, F. Bosc, I. Karacan, B. Milthorpe, C. Drouet, Brushite $(\mathrm{Ca}, \mathrm{M}) \mathrm{HPO}_{4}, 2 \mathrm{H}_{2} \mathrm{O}$ doping with bioactive ions $\left(\mathrm{M}=\mathrm{Mg}^{2+}\right.$, $\mathrm{Sr}^{2+}, \mathrm{Zn}^{2+}, \mathrm{Cu}^{2+}$, and $\left.\mathrm{Ag}^{+}\right)$: a new path to functional biomaterials?, Mater. Today Chem. 16 (2020). https://doi.org/10.1016/j.mtchem.2019.100230.

[41] R.J. Coleman, G. Lawrie, L.K. Lambert, M. Whittaker, K.S. Jack, L. Grondahl, Phosphorylation of alginate: Synthesis, characterization, and evaluation of in vitro mineralization capacity, Biomacromolecules. 12 (2011) 889-897. https://doi.org/10.1021/bm1011773.

[42] C. Rey, C. Combes, C. Drouet, D. Grossin, G. Bertrand, J. Soulié, Bioactive calcium phosphate compounds: Physical chemistry, 2017. https://doi.org/10.1016/B978-0-12-803581-8.10171-7.

[43] M. Bohner, Reactivity of calcium phosphate cements, J. Mater. Chem. 17 (2007) 3980-3986. https://doi.org/10.1039/b706411j.

[44] A. El-Fiqi, J.H. Kim, R.A. Perez, H.W. Kim, Novel bioactive nanocomposite cement formulations with potential properties: incorporation of the nanoparticle form of mesoporous bioactive glass into calcium phosphate cements, J. Mater. Chem. B. 3 (2015) 1321-1334. https://doi.org/10.1039/c4tb01634c. 
[45] A.C.M. Renno, M.R. Nejadnik, F.C.J. Van De Watering, M.C. Crovace, E.D. Zanotto, J.P.M. Hoefnagels, J.G.C. Wolke, J.A. Jansen, J.J.J.P. Van Den Beucken, Incorporation of bioactive glass in calcium phosphate cement: Material characterization and in vitro degradation, J. Biomed. Mater. Res. - Part A. 101 A (2013) 2365-2373. https://doi.org/10.1002/jbm.a.34531.

[46] C.-H. David Chen, C.-C. Chen, M.-Y. Shie, C.-H. Huang, S.-J. Ding, Controlled release of gentamicin from calcium phosphate/alginate bone cement, Mater. Sci. Eng. C. 31 (2011) 334-341. https://doi.org/10.1016/j.msec.2010.10.002.

[47] H.J. Lee, B. Kim, A.R. Padalhin, B.T. Lee, Incorporation of chitosan-alginate complex into injectable calcium phosphate cement system as a bone graft material, Mater Sci Eng C Mater Biol Appl. 94 (2019) 385-392. https://doi.org/10.1016/j.msec.2018.09.039.

[48] J. Zhang, W. Liu, V. Schnitzler, F. Tancret, J.M. Bouler, Calcium phosphate cements for bone substitution: Chemistry, handling and mechanical properties, $\begin{array}{llll}\text { Acta } & \text { Biomater. } & 10 & \text { (2014) }\end{array}$ https://doi.org/10.1016/j.actbio.2013.11.001.

[49] S. Tadier, L. Galea, B. Charbonnier, G. Baroud, M. Bohner, Phase and size separations occurring during the injection of model pastes composed of $\beta$ tricalcium phosphate powder, glass beads and aqueous solutions, Acta Biomater. 10 (2014) 2259-2268. https://doi.org/10.1016/j.actbio.2013.12.018.

[50] J. Åberg, J. Engstrand, H. Engqvist, Influence of particle size on hardening and handling of a premixed calcium phosphate cement, J. Mater. Sci. Mater. Med. 24 (2013) 829-835. https://doi.org/10.1007/s10856-013-4855-z.

[51] S. Sprio, M. Dapporto, M. Montesi, S. Panseri, W. Lattanzi, E. Pola, G. Logroscino, A. Tampieri, Novel Osteointegrative Sr-Substituted Apatitic Cements Enriched with Alginate, Mater. 9 (2016). 
https://doi.org/10.3390/ma9090763.

[52] H. Zhou, T.J.F. Luchini, S.B. Bhaduri, L. Deng, T.J.F. Luchini, S.B. Bhaduri, L.D.S. Si, H. Zhou, T.J.F. Luchini, S.B. Bhaduri, L. Deng, Silicon ( Si ) containing bone cements : a review Silicon ( $\mathrm{Si}$ ) containing bone cements : a review, 7857 (2016). https://doi.org/10.1179/17535557B15Y.000000005.

[53] A. Bigi, B. Bracci, S. Panzavolta, Effect of added gelatin on the properties of calcium phosphate cement, Biomaterials. 25 (2004) 2893-2899.

https://doi.org/10.1016/j.biomaterials.2003.09.059. 


\section{Legend Figures}

Figure 1. Characteristics of the bioactive glass powder (MB): FTIR spectra (a), XRD diffractogram (b), SEM micrograph (c), and its EDS profile (d).

Figure 2. XRD patterns of MB, Vaterite, DCPD, Alg, CPC, CPC-MB 25, and CPCMB25-Alg5 (A: Apatite, V: Vaterite).

Figure 3. FTIR spectra of MB, Vaterite, DCPD, Alg, CPC, CPC-MB25, and CPCMB25-Alg 5.

Figure 4. SEM micrographs of Vaterite (a), DCPD (b), MB (c), Alg (d), CPC (e, f, and g), CPC-MB25 (h, i, and j), CPC-MB25-Alg5 (k, 1, and m) and the EDS spectra of Vaterite (V), Apatite (A), Bioactive glass (MB). P refers to Pore.

Figure 5. XRD patterns and FTIR spectra of CPC, CPC-MB25, and CPC-MB25-Alg5 at 2, 4, 6, 24, and 48-hour of setting reaction (D: DCPD, V: Vaterite, and A: Apatite).

Figure 6. Intensity ratio $\left(\mathrm{I}_{\mathrm{Ap}} / \mathrm{I}_{\mathrm{Vat}}\right)$ obtained from the XRD patterns of CPC, CPCMB25, and CPC-MB25-Alg5 materials as a function of incubation time.

Figure 7. Photos of CPC, CPC-MB25, and CM-MB25-Alg5 cements injected into $\mathrm{NaCl}$ solution. Photos were taken after 5 minutes and 24 hours of immersion in $\mathrm{NaCl}$ solution.

Figure 8. Injectability of formulated cement pastes.

Figure 9. Compressive strength of prepared materials. 


\section{Tables}

Table 1. Different formulations of the composite cements and their composition.

Table 2. Porosity values for CPC, CPC-BG25, and CPC-BG25-Alg5.

Table 3: Initial $\left(t_{i}\right)$ and final $\left(t_{f}\right)$ setting times of prepared cements and composites. 


\section{Tables}

Table 1. Different formulations of the composite cements and their composition.

\begin{tabular}{|c|c|c|c|c|c|}
\hline \multirow[b]{2}{*}{ Samples } & \multicolumn{3}{|c|}{ Solid-phase } & \multirow[b]{2}{*}{$\begin{array}{c}\text { Liquid } \\
\text { phase }\end{array}$} & \multirow[b]{2}{*}{$\mathbf{L} / \mathbf{P}$} \\
\hline & $\begin{array}{l}\mathrm{CaCO}_{3} \\
(\% \text { wt })\end{array}$ & $\begin{array}{l}\text { DCPD } \\
(\% \text { wt })\end{array}$ & $\begin{array}{c}\text { BG } \\
(\% \text { wt })\end{array}$ & & \\
\hline CPC & 50.0 & 50.0 & 0 & $\begin{array}{l}\text { Distilled } \\
\text { water }\end{array}$ & 0.7 \\
\hline CPC-BG10 & 45.0 & 45.0 & 10 & \multirow{3}{*}{$\begin{array}{l}\text { Distilled } \\
\text { water }\end{array}$} & \multirow{3}{*}{0.7} \\
\hline CPC-BG15 & 42.5 & 42.5 & 15 & & \\
\hline CPC-BG25 & 37.5 & 37.5 & 25.0 & & \\
\hline CPC-BG25-Alg1 & 37.5 & 37.5 & 25.0 & Alg 1wt $\%$ & \multirow{3}{*}{0.7} \\
\hline CPC-BG25-Alg3 & 37.5 & 37.5 & 25.0 & Alg 3 wt \% & \\
\hline CPC-BG25-Alg5 & 37.5 & 37.5 & 25.0 & $\operatorname{Alg} 5 \mathrm{wt} \%$ & \\
\hline
\end{tabular}

Table 2. Porosity values for CPC, CPC-BG25, and CPC-BG25-Alg5.

\begin{tabular}{l|c|c|c}
\hline Materials & CPC & CPC-BG25 & CPC-BG25-Alg5 \\
\hline $\begin{array}{l}\text { Porosity volume } \\
\left(\mathbf{m m}^{3} / \mathbf{g}\right)\end{array}$ & 856 & 504 & 362 \\
\hline
\end{tabular}


Table 3: Initial $\left(\mathrm{t}_{\mathrm{i}}\right)$ and final $\left(\mathrm{t}_{\mathrm{f}}\right)$ setting times of prepared cements and composites.

\begin{tabular}{lcc}
\hline Sample & $\mathbf{t}_{\mathbf{i}}(\mathbf{m i n})$ & $\mathbf{t}_{\mathbf{f}}(\mathbf{m i n})$ \\
\hline CPC & $75 \pm 3$ & $119 \pm 5$ \\
\hline CPC-BG10 & $61 \pm 2$ & $88 \pm 4$ \\
\hline CPC-BG15 & $53 \pm 3$ & $82 \pm 3$ \\
\hline CPC-BG25 & $42 \pm 3$ & $65 \pm 3$ \\
\hline CPC-BG25-Alg1 & $50 \pm 3$ & $83 \pm 4$ \\
\hline CPC-BG25-Alg3 & $62 \pm 3$ & $105 \pm 2$ \\
\hline CPC-BG25-Alg5 & $73 \pm 3$ & $121 \pm 4$ \\
\hline
\end{tabular}




\section{Figures List}

Fig.1

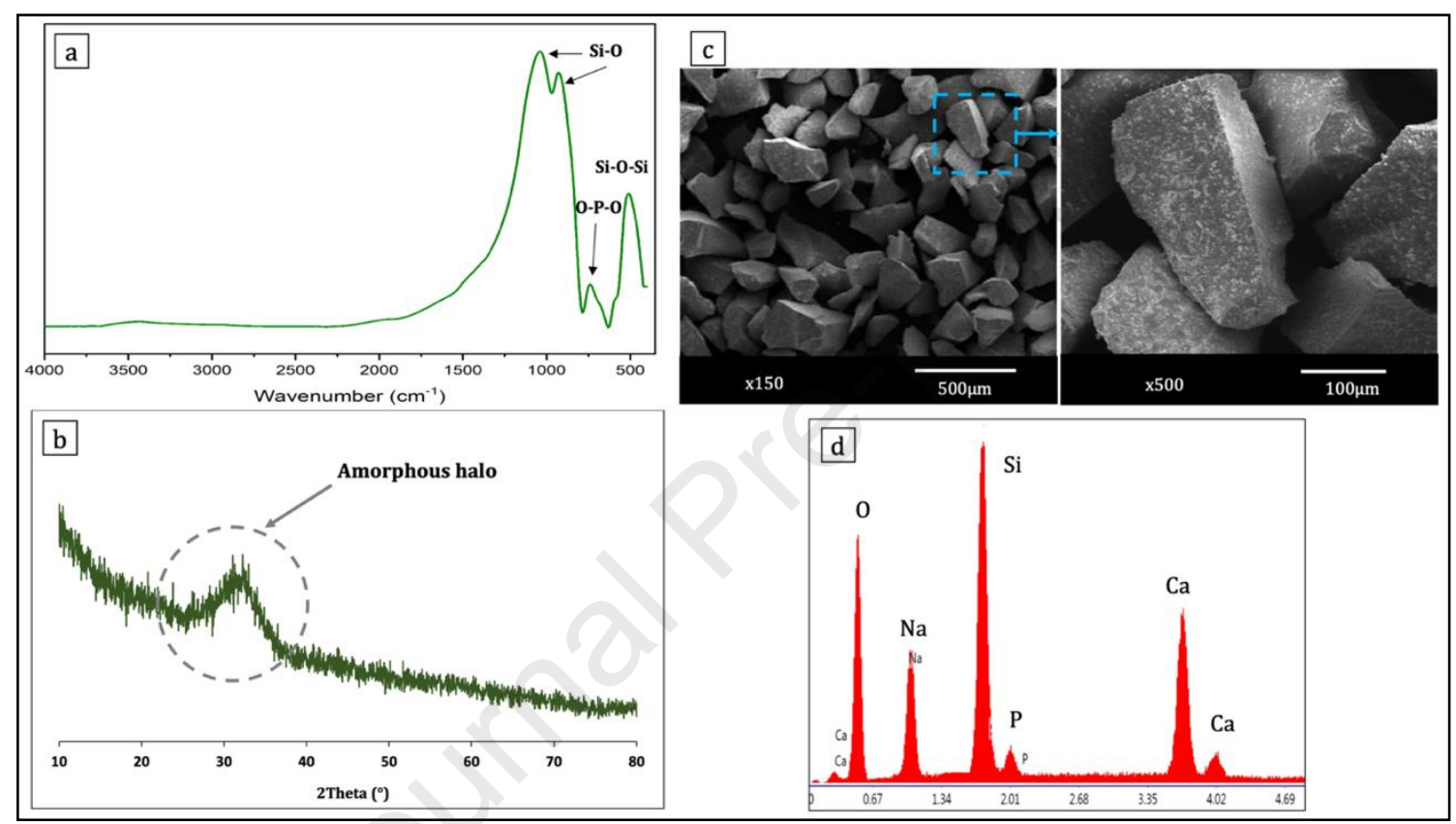


Fig.2.
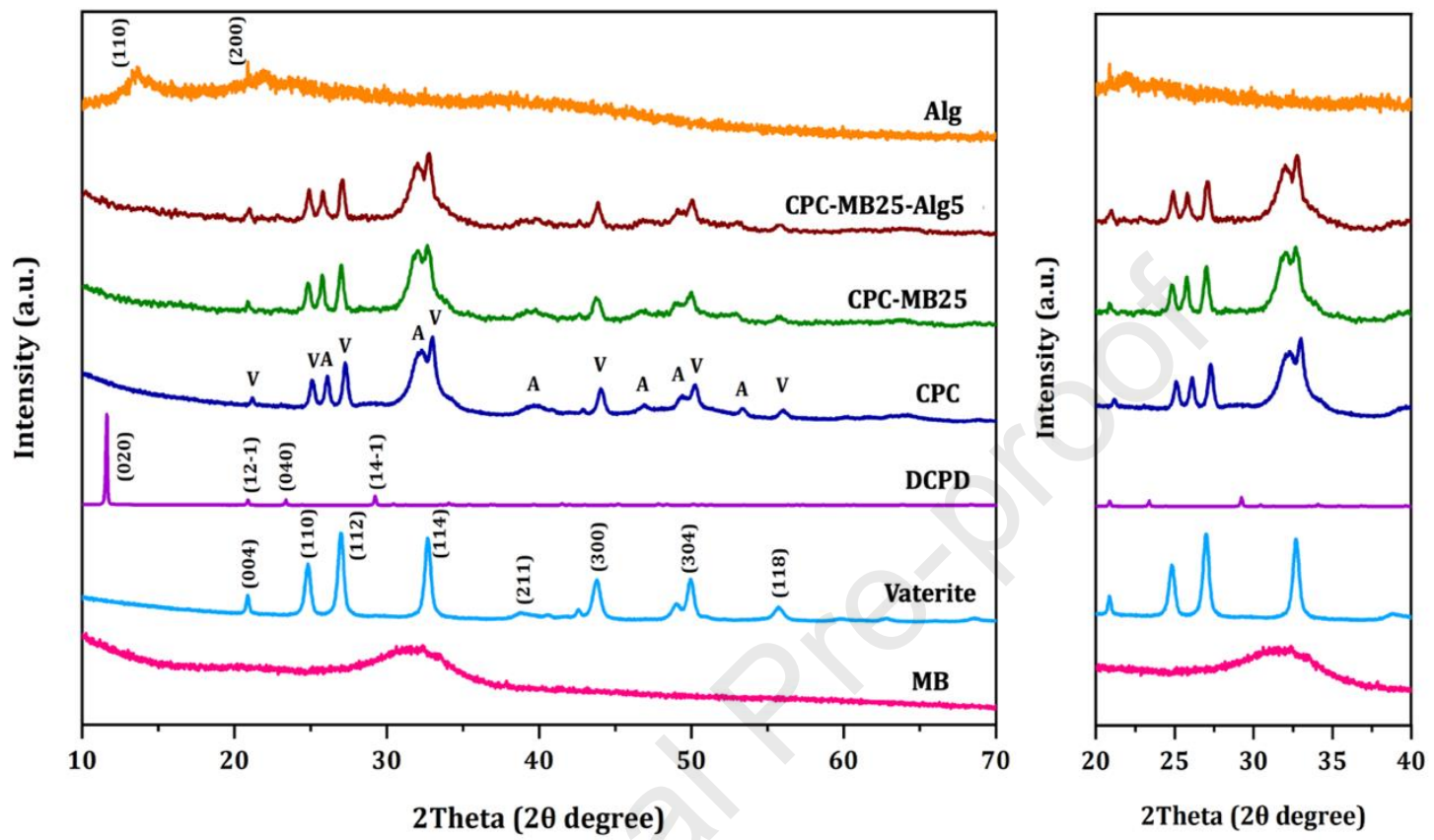
Fig.3.

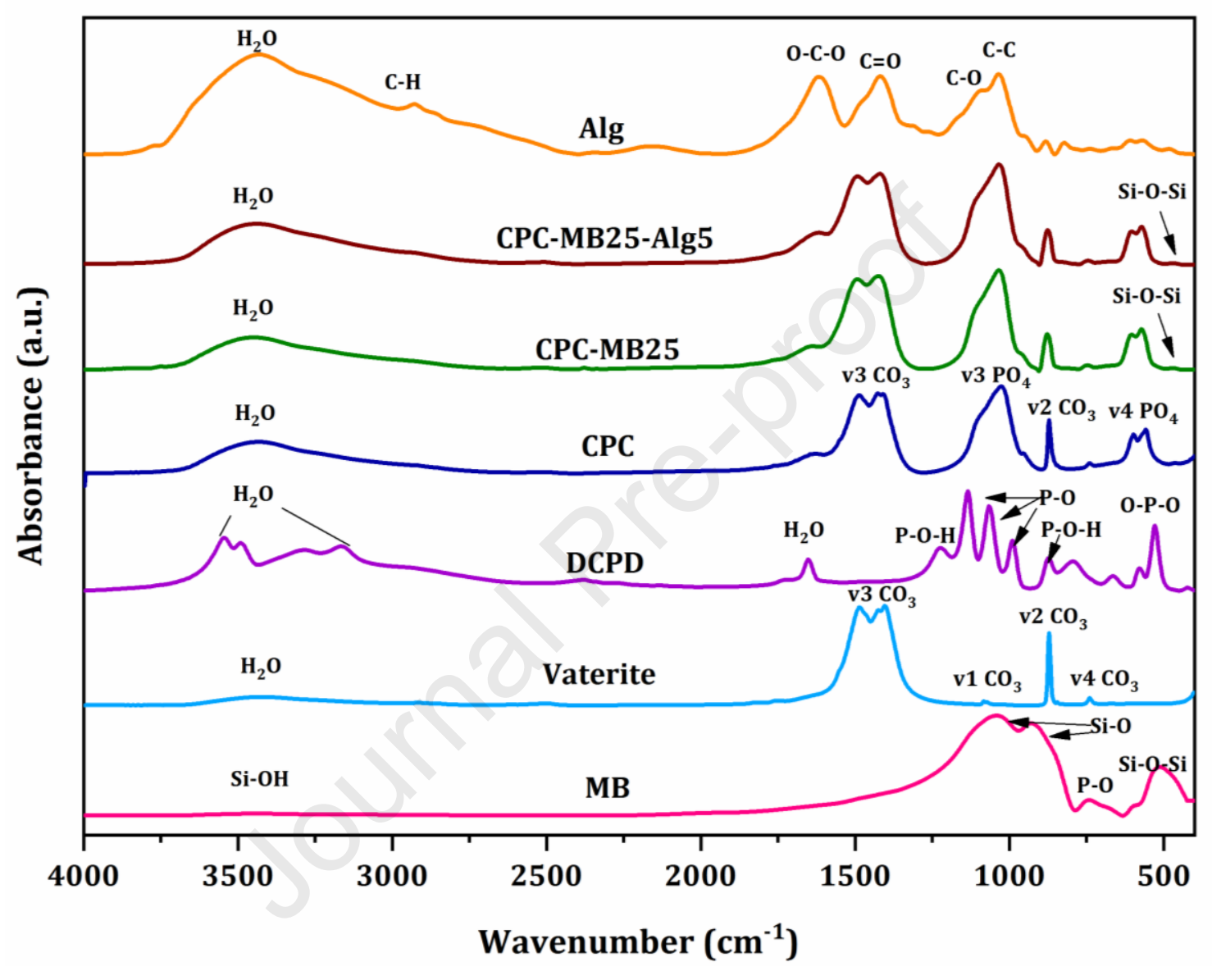


Fig.4.

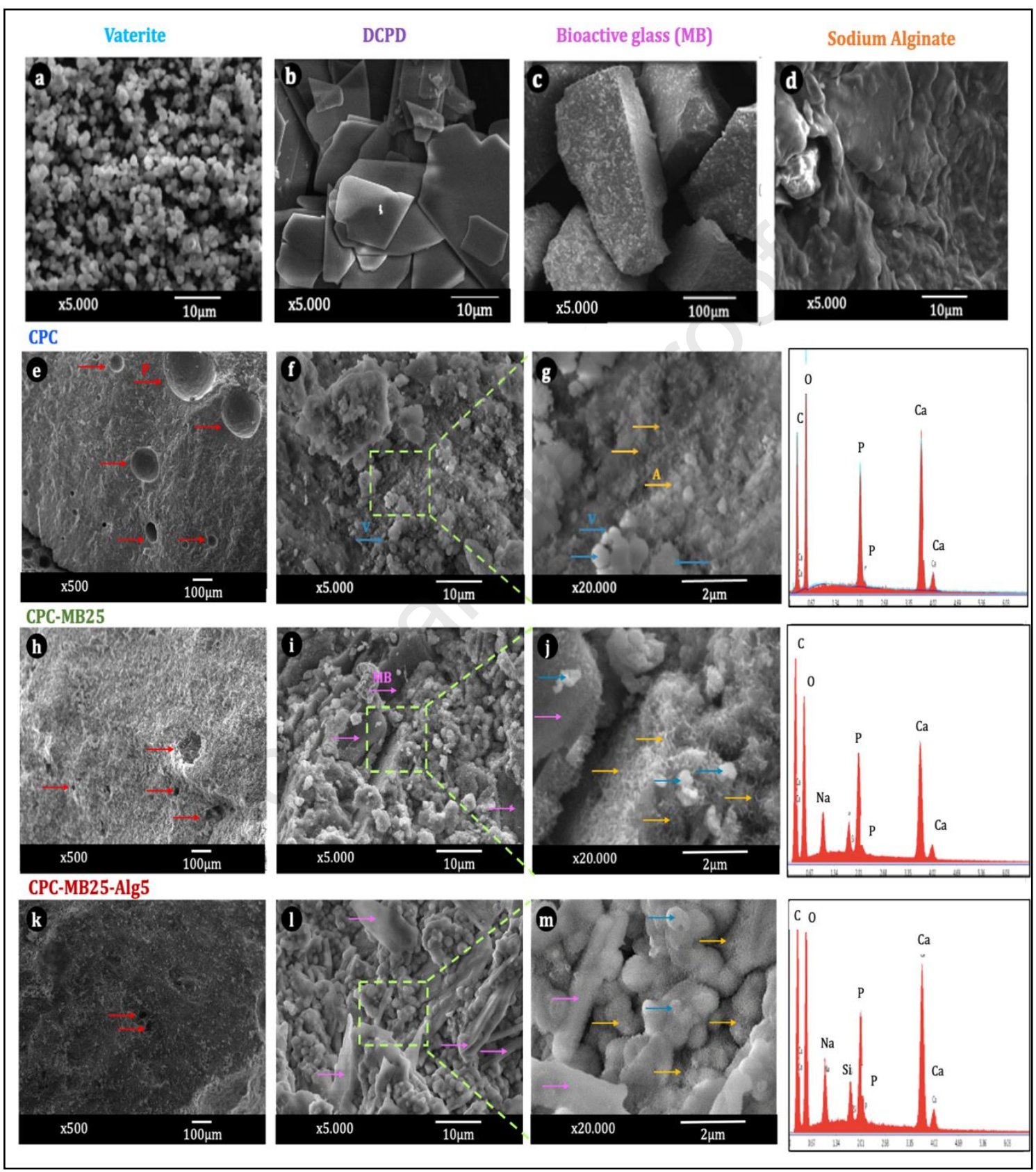


Fig.5.

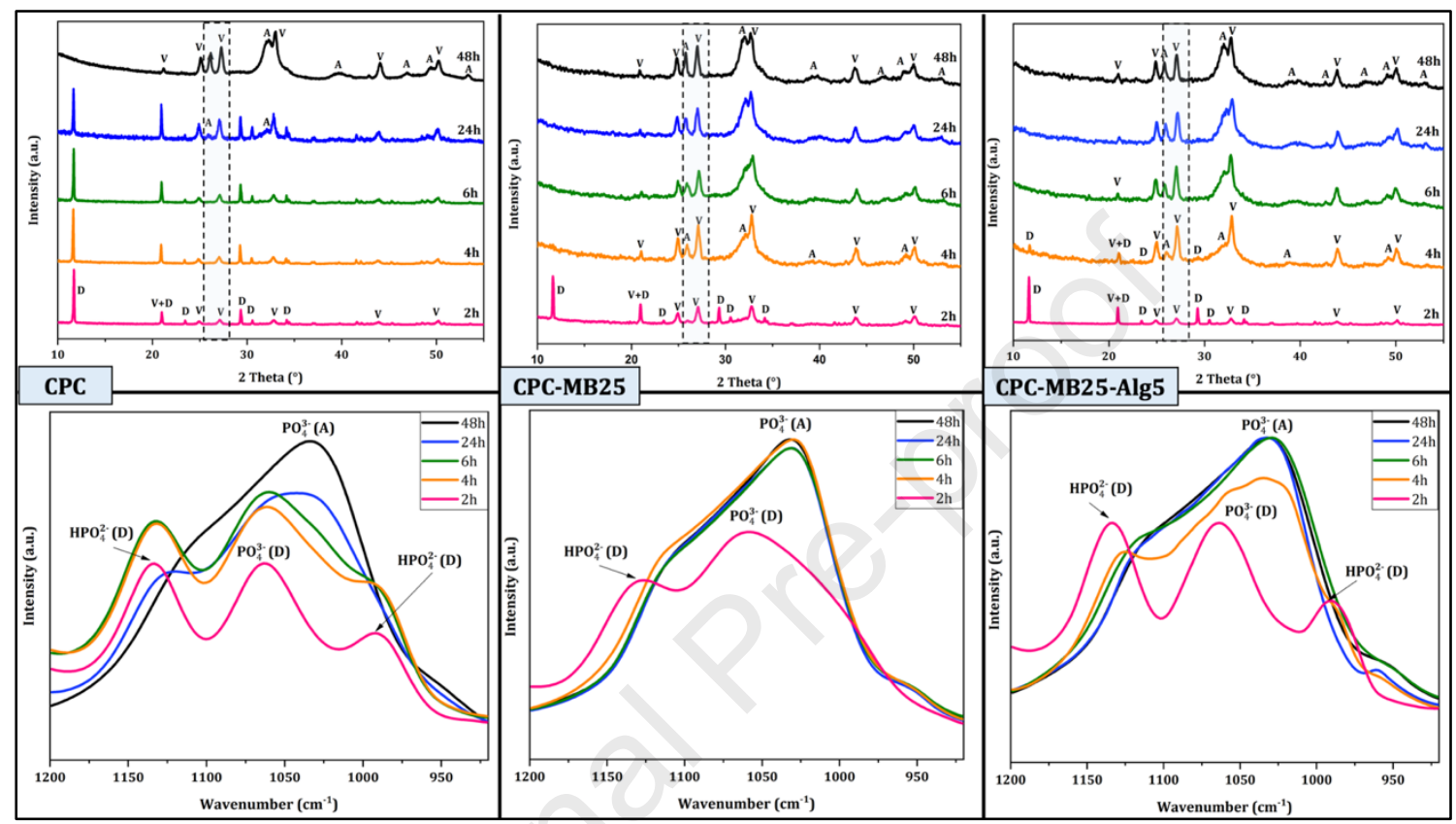


Fig.6.
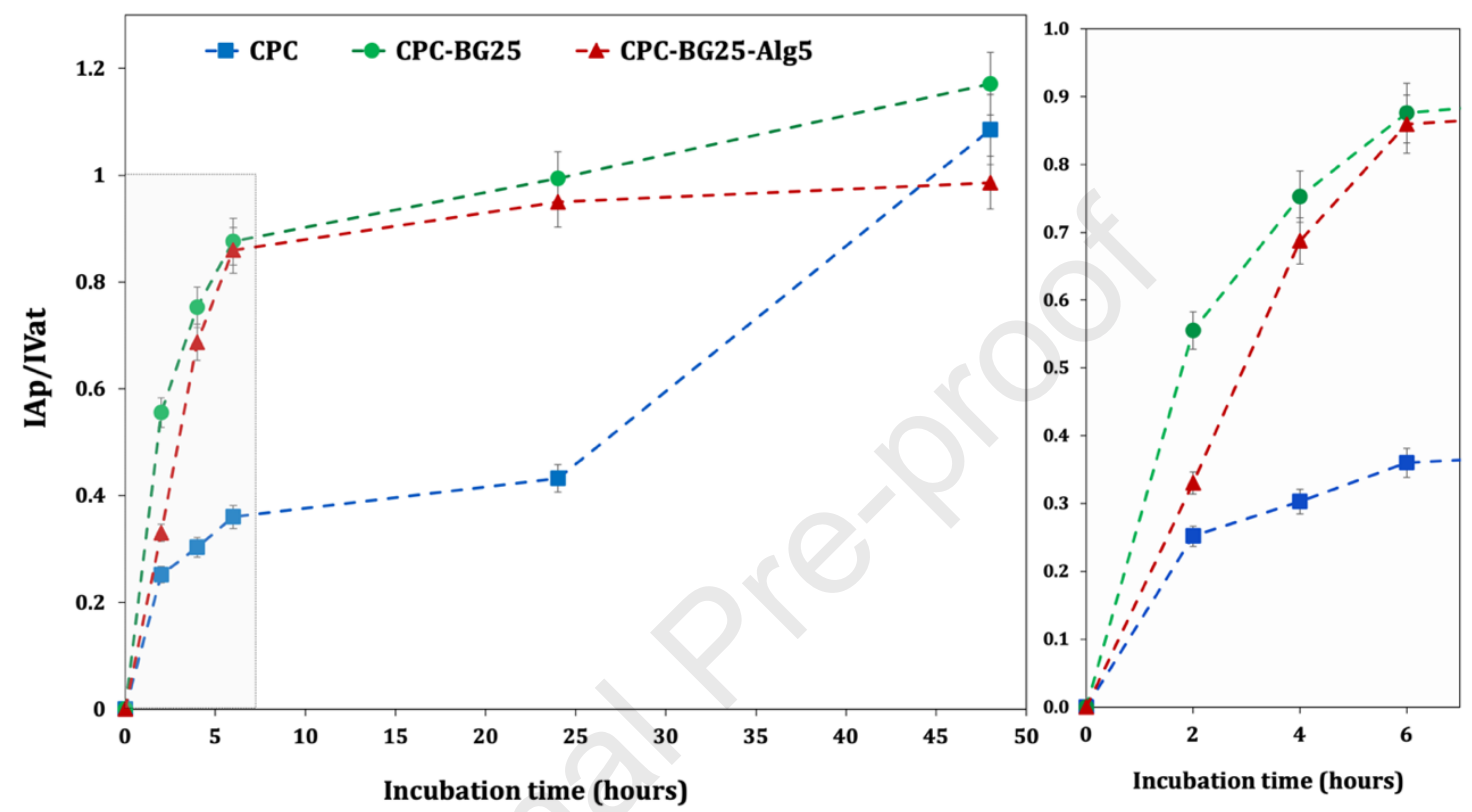
Fig.7.

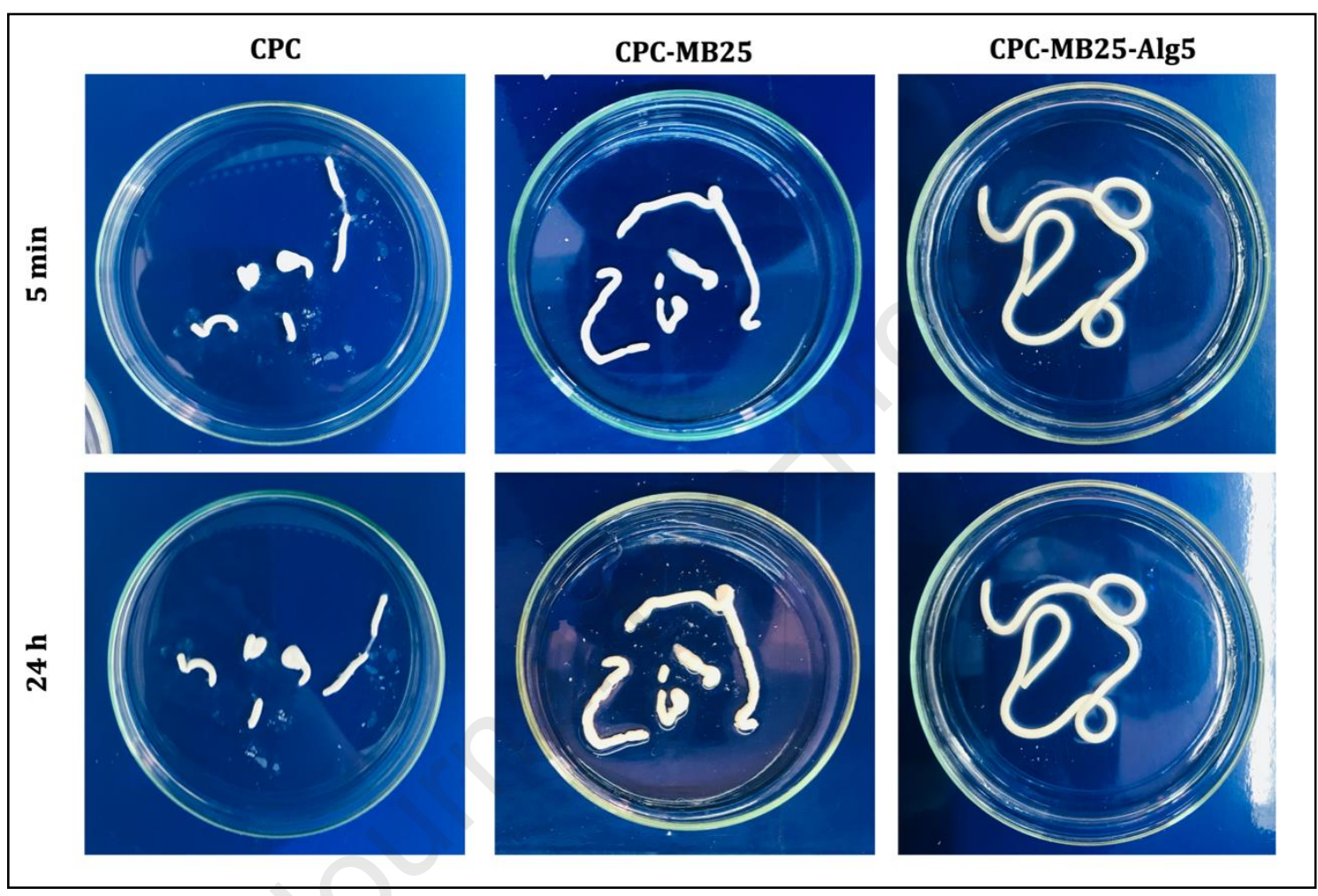


Fig.8.

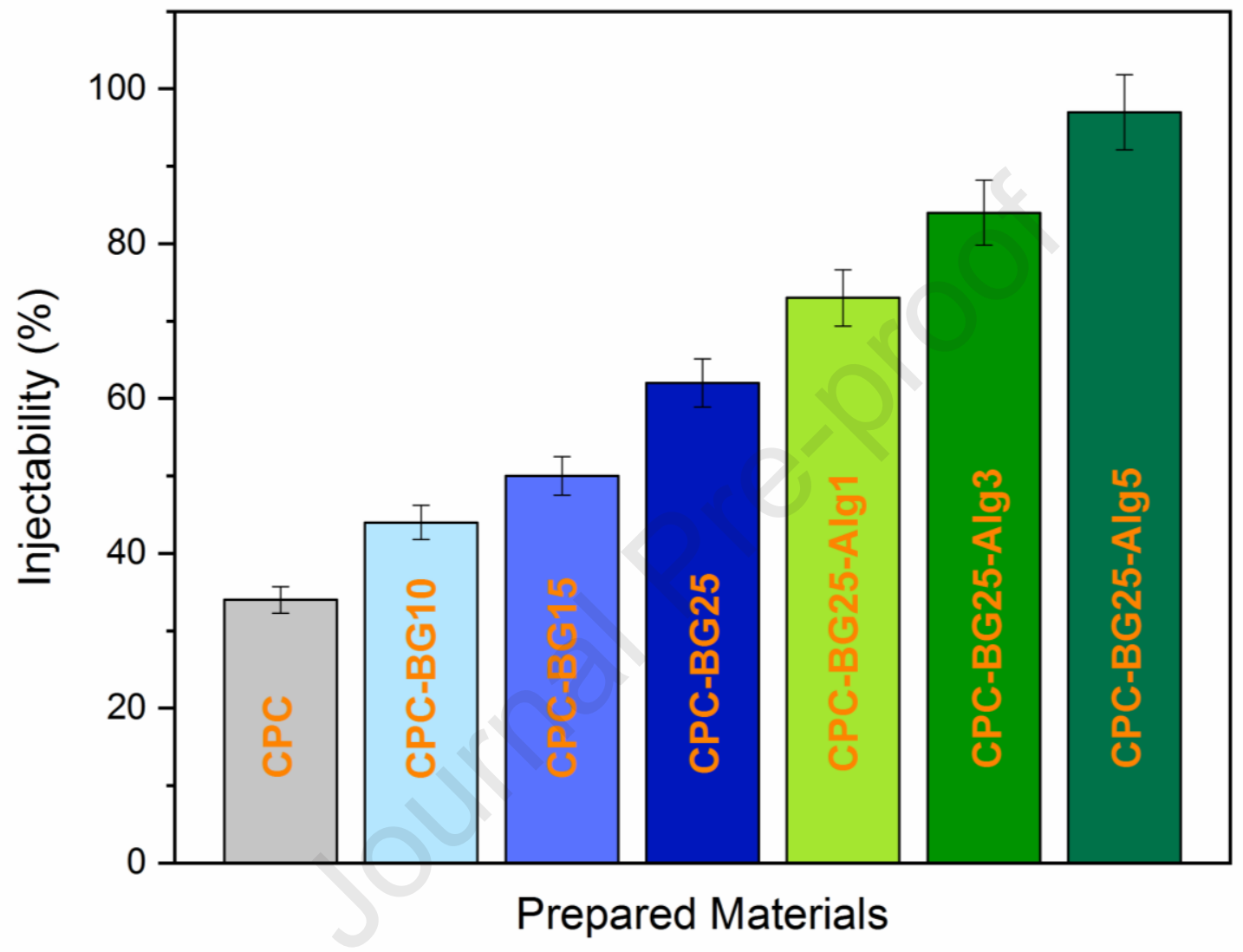


Fig.9.

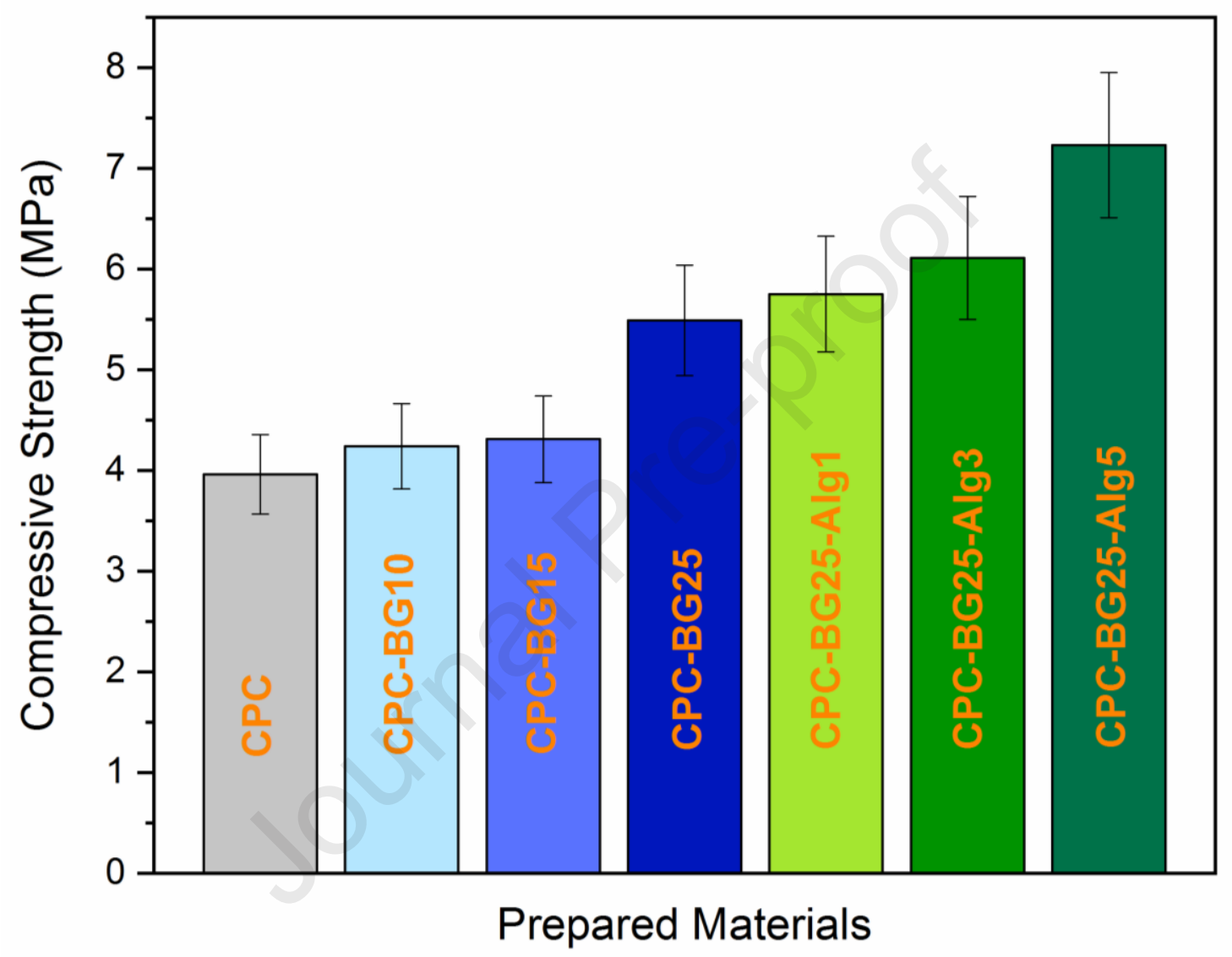




\section{Declaration of interests}

$\bigotimes$ The authors declare that they have no known competing financial interests or personal relationships that could have appeared to influence the work reported in this paper.

$\square$ The authors declare the following financial interests/personal relationships which may be considered as potential competing interests:

The authors declare no conflict of interest 